Article

\title{
The Diversity, Metabolomics Profiling, and the Pharmacological Potential of Actinomycetes Isolated from the Estremadura Spur Pockmarks (Portugal)
}

\author{
António Pinto-Almeida 1,2,3 ${ }^{\mathbb{D}}$, Anelize Bauermeister ${ }^{4}$, Luca Luppino ${ }^{1,2,5}$, Inês R. Grilo ${ }^{1,2} \mathbb{D}^{\text {, Juliana Oliveira }}{ }^{1,2}$, \\ Joana R. Sousa ${ }^{1,2}$, Daniel Petras ${ }^{6}$, Clara F. Rodrigues ${ }^{7} \mathbb{D}$, Alejandra Prieto-Davó ${ }^{8} \mathbb{D}$, Deniz Tasdemir ${ }^{9,10} \mathbb{D}$, \\ Rita G. Sobral ${ }^{1,2}$ (D) and Susana P. Gaudêncio ${ }^{1,2, * \mathbb{D}}$
}

1 Associate Laboratory i4HB-Institute for Health and Bioeconomy, NOVA School of Science and Technology, NOVA University Lisbon, 2819-516 Caparica, Portugal; pintoalmeida84@gmail.com (A.P.-A.); luppinoluca00@gmail.com (L.L.); inesgrilo@fct.unl.pt (I.R.G.); jpc.oliveira@campus.fct.unl.pt (J.O.); jrl.sousa@campus.fct.unl.pt (J.R.S.); rgs@fct.unl.pt (R.G.S.)

2 UCIBIO-Applied Molecular Biosciences Unit, NOVA School of Science and Technology, NOVA University of Lisbon, 2819-516 Caparica, Portugal

3 Instituto de Engenharias e Ciências do Mar, Universidade Técnica do Atlântico, 163 Ribeira de Julião, 163 Mindelo, Cape Verde

4 Skaggs School of Pharmacy \& Pharmaceutical Science, University of California San Diego, La Jolla, CA 92093-075, USA; abauermeister@health.ucsd.edu

5 Dipartimento di Scienze Della Vita, Università Degli Studi di Modena e Reggio Emilia, 41125 Modena, Italy

6 CMFI Cluster of Excellence, Interfaculty Institute of Microbiology and Medicine, University of Tuebingen,

check for updates

Citation: Pinto-Almeida, A.; Bauermeister, A.; Luppino, L.; Grilo, I.R.; Oliveira, J.; Sousa, J.R.; Petras, D.; Rodrigues, C.F.; Prieto-Davó, A.; Tasdemir, D.; et al. The Diversity, Metabolomics Profiling, and the Pharmacological Potential of Actinomycetes Isolated from the Estremadura Spur Pockmarks (Portugal). Mar. Drugs 2022, 20, 21. https://doi.org/10.3390/ md20010021

Academic Editor: Ipek Kurtboke

Received: 18 November 2021

Accepted: 14 December 2021

Published: 23 December 2021

Publisher's Note: MDPI stays neutral with regard to jurisdictional claims in published maps and institutional affiliations.

Copyright: (C) 2021 by the authors. Licensee MDPI, Basel, Switzerland. This article is an open access article distributed under the terms and conditions of the Creative Commons Attribution (CC BY) license (https:// creativecommons.org/licenses/by/ $4.0 /)$. Auf der Morgenstelle 24, 72076 Tuebingen, Germany; daniel.petras@uni-tuebingen.de

7 CESAM-Centre for Environmental and Marine Studies, Department of Biology, University of Aveiro, 3810-193 Aveiro, Portugal; clara.rodrigues@ua.pt

8 Unidad de Química-Sisal, Facultad de Química, Universidad Nacional Autónoma de México, Sisal 97356, Mexico; apdavo@unam.mx

9 GEOMAR Centre for Marine Biotechnology, Research Unit Marine Natural Products Chemistry, GEOMAR Helmholtz Centre for Ocean Research Kiel, 24106 Kiel, Germany; dtasdemir@geomar.de

10 Faculty of Mathematics and Natural Sciences, Kiel University, Christian-Albrechts-Platz 4, 24118 Kiel, Germany

* Correspondence: s.gaudencio@fct.unl.pt; Tel.: +35-12-1294-8300; Fax: +35-12-1294-8550

\begin{abstract}
The Estremadura Spur pockmarks are a unique and unexplored ecosystem located in the North Atlantic, off the coast of Portugal. A total of 85 marine-derived actinomycetes were isolated and cultured from sediments collected from this ecosystem at a depth of 200 to $350 \mathrm{~m}$. Nine genera, Streptomyces, Micromonospora, Saccharopolyspora, Actinomadura, Actinopolymorpha, Nocardiopsis, Saccharomonospora, Stackebrandtia, and Verrucosispora were identified by $16 \mathrm{~S}$ rRNA gene sequencing analyses, from which the first two were the most predominant. Non-targeted LC-MS/MS, in combination with molecular networking, revealed high metabolite diversity, including several known metabolites, such as surugamide, antimycin, etamycin, physostigmine, desferrioxamine, ikarugamycin, piericidine, and rakicidin derivatives, as well as numerous unidentified metabolites. Taxonomy was the strongest parameter influencing the metabolite production, highlighting the different biosynthetic potentials of phylogenetically related actinomycetes; the majority of the chemical classes can be used as chemotaxonomic markers, as the metabolite distribution was mostly genera-specific. The EtOAc extracts of the actinomycete isolates demonstrated antimicrobial and antioxidant activity. Altogether, this study demonstrates that the Estremadura Spur is a source of actinomycetes with potential applications for biotechnology. It highlights the importance of investigating actinomycetes from unique ecosystems, such as pockmarks, as the metabolite production reflects their adaptation to this habitat.
\end{abstract}

Keywords: marine-derived actinomycetes; actinobacteria; Estremadura Spur pockmarks; molecular networking; metabolomics; Qemistree; antimicrobial activity; marine natural products; blue biotechnology 


\section{Introduction}

Pockmarks are seabed culminations of fluid (liquid or gas) migrations through the sedimentary column and their escape to the seawater, which appear as cone-shaped circular or elliptical depressions [1]. Some are active, seeping oil or methane, while others are dormant or inactive. Active pockmarks are well-studied since they harbor specialized microbial communities capable of metabolizing compounds such as methane and other hydrocarbons, and such communities are not found in inactive pockmarks [2]. Inactive pockmarks can present microbial communities that are totally different from the surrounding environment and are poorly studied, highlighting the importance of exploring these ecosystems [2]. The Estremadura Spur pockmark field, off the coast of continental Portugal, is the first documented evidence of fluid seepage in the Lusitanian Basin, a Mesozoic rifted basin containing promising hydrocarbon occurrences [3]. This field of pockmarks exhibits individual pockmarks up to $120 \mathrm{~m}$ in diameter and $10 \mathrm{~m}$ in depth and is located at a depth of 200 to $350 \mathrm{~m}$. These pockmarks are considered inactive, as they were covered by recent sediments. The stacking of various pockmarks suggests a cyclical fluid flow of activity, possibly resulting from the eustatic sea level variations and changes in hydrostatic pressure [3].

Actinomycetes are a chemically prolific source of bioactive secondary metabolites [4] and are of commercial importance, such as enzymes of industrial interest [5] and lead structures for the development of new drugs [6]. They produce the majority of the existing naturally occurring antibiotics (ca. 75\%) [7,8], mostly obtained from soil Streptomyces [9]. The genetic and metabolic diversity of marine actinomycetes reflects their adaptation throughout evolution to their particular marine conditions [10-14]. Salinosporamide A (Marizomib ${ }^{\mathrm{TM}}$ ), currently in phase III clinical trials for the treatment of glioblastoma, is the metabolite that better highlights the importance of marine-derived actinomycetes [15-17]. The bottom of the ocean is an important source for novel actinomycetes and the associated metabolites [10-14]. Nevertheless, the difficulty in accessing challenging marine environments has hindered the exploration of their biodiversity and their distribution along the seafloor is still largely unknown. The description of indigenous marine actinomycetes in the ocean remains underexplored.

This study aimed to explore the biological and chemical diversity of cultivable actinomycetes from the Estremadura Spur pockmarks, and to evaluate their ability to produce metabolites with antimicrobial (antibacterial, antiyeast, and antifungal), anticancer, and antioxidant activities. This is the first study reporting the targeted culture-dependent identification of actinomycetes from the Estremadura Spur pockmarks, their metabolomics profile, and their biotechnological potential.

\section{Results and Discussion}

\subsection{Cultivable Actinomycetes' Phylogeny and Diversity}

A total of 85 actinomycete isolates were cultivated from the Estremadura Spur sediments (Figure 1) and their 16S rRNA sequences were compared to the NCBI and EzTaxon databases. No chimeric sequences were identified.

For the taxonomic classification at the species level of some isolates, further phylogenetic analyses were used for clarification (see the "Materials and Methods" in Section 3 and Figure S1 in Supplementary Materials). Overall, nine different genera were discovered: Streptomyces, Micromonospora, Verrucosispora, Nocardiopsis, Actinomadura, and the rare genera Saccharomonospora, as well as Saccharopolyspora, Stackebrandtia, and Actinopolymorpha. The genera Streptomyces and Micromonospora are by far the most abundant ones (Figure 2A). The high abundance of these two genera agrees with previous studies [6,18-22], including work from our group that was performed with actinomycetes collected off the Madeira Archipelago, Portugal [23], suggesting that these genera are very abundant in all oceans, or the media used in the reported studies selects for them. In total, $21.2 \%(n=85)$ of the Estremadura Spur isolates required seawater for growth, suggesting that they are obligate marine actinomycetes (Figure 2B and Figure S1, highlighted with black stars, and Table S3). 
Although marine obligate Salinispora strains have been recovered from shallow water samples from the Madeira Archipelago, Portugal $[23,24]$, this genus was not recovered from the Estremadura Spur sediments, which also supports the hypothesis that these pockmarks present a differentiated microbial community.

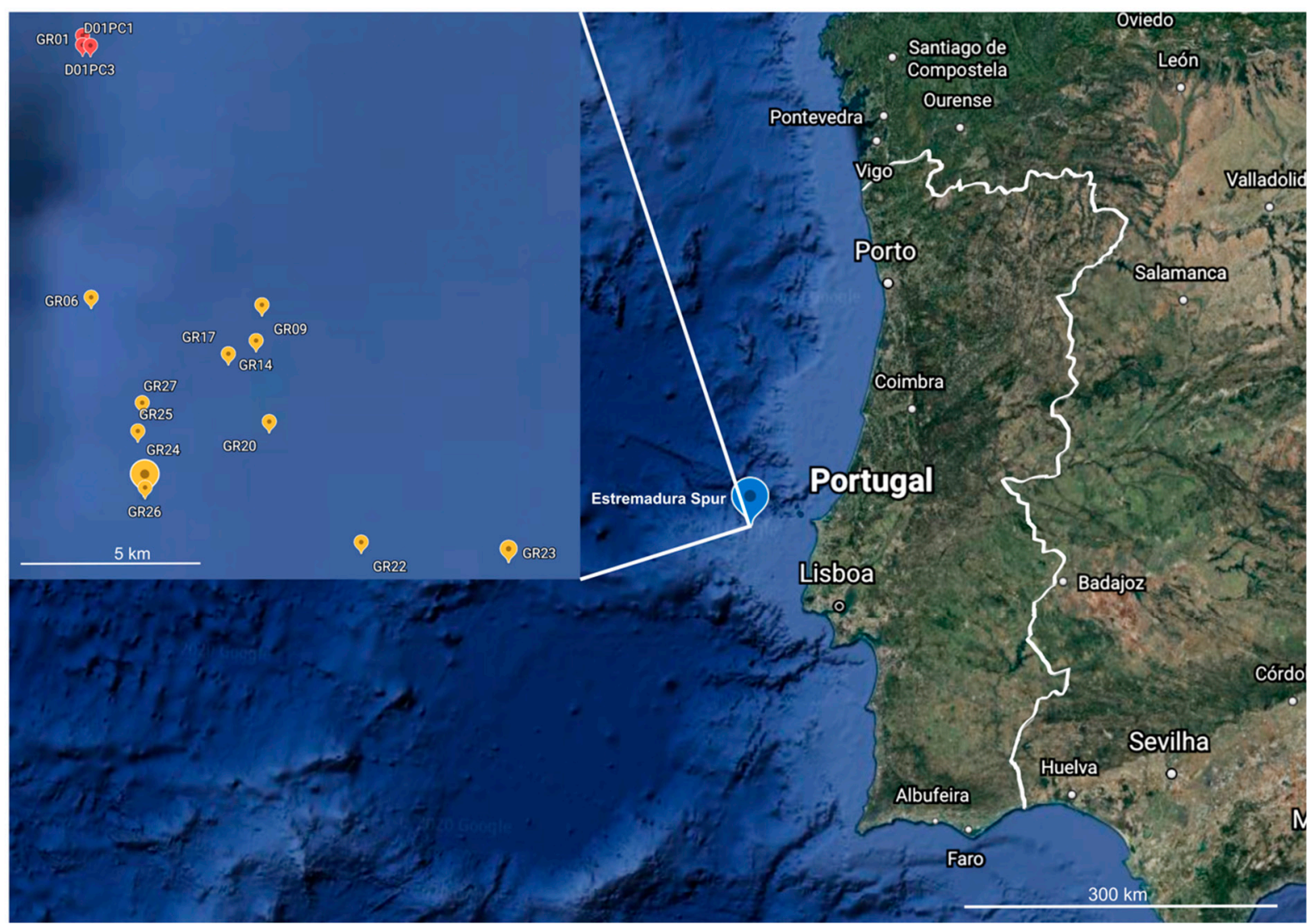

Figure 1. Geographical location of the Estremadura Spur, continental Portugal coast, with the locations of the marine sediment collection stations zoomed in. The collection points marked in red correspond to small mounds and those in yellow correspond to pockmarks. This map was retrieved from Google Earth (https: / / earth.google.com/web / accessed on 25 September 2021).

Different media were used to isolate the actinomycetes. The A1 medium allowed the isolation of only six strains belonging to Streptomyces, Micromonospora, and Verrucosispora, reducing concentrations to one half ( $\frac{1}{2} \mathrm{~A} 1$ medium), which allowed the growth of a higher number of strains (24 strains) from Streptomyces, Micromonospora, and Saccharopolyspora. The SWA medium allowed the highest number of actinomycete isolates, 56 strains, from all the obtained genera, except Verrucosispora. The isolation of actinomycetes was clearly favored by the SWA medium.

Fifty-three operational taxonomic units (OTUs) were defined (at 97\% sequence identity with their nearest BLASTn neighbor) under the nine different genera of cultivated actinomycetes (Table 1, Figure 2A). From these, 24 OTUs (35 isolates) belonged to Streptomyces and 19 OTUs (30 isolates) to Micromonospora. 
Table 1. Genera and number of isolates, OTUs, and species for each genus isolated from the Estremadura Spur, continental Portugal coast marine sediments.

\begin{tabular}{cccc}
\hline Genus & Number of Isolates & Number of OTUs & Number of Species \\
\hline Streptomyces & 35 & 24 & 13 \\
Micromonospora & 30 & 19 & 16 \\
Saccharopolyspora & 6 & 2 & 1 \\
Saccharomonospora & 5 & 2 & 1 \\
Actinomadura & 3 & 2 & 2 \\
Nocardiopsis & 3 & 1 & 1 \\
Actinopolymorpha & 1 & 1 & 1 \\
Stackebrandtia & 1 & 1 & 1 \\
Verrucosispora & 1 & 1 & 1 \\
Total & 85 & 53 & 37 \\
\hline
\end{tabular}

The phylogenetic tree revealed that the higher recovery of these two genera resulted in higher microbial diversity within them (Figure 2B). The remaining genera were represented each by a single branch in the $16 \mathrm{~S}$ rRNA molecular phylogenetic tree, suggesting that these actinomycete genera are either less adaptable to the used cultivation conditions, or that their microbial diversity in the Estremadura Spur sediments is low. All strains had more than a $98 \%$ sequence identity with their nearest BLASTn neighbor. However, six out of the nine genera recovered by cultivation included strains with seawater requirements for growth (Figure 2B), suggesting they could well represent different species from those neighbors. This finding poses new questions about the evolution of marine actinomycete strains in the Atlantic Ocean, as this is the third study in which our group found a high abundance of seawater requiring strains from these waters [23-25]. Furthermore, seawater-requiring strains are found in more than $50 \%$ of the recovered genera, while work from other oceanic locations describes this trait as one that has mostly been reported for Streptomyces and Salinispora [14,21,26-29]. Amongst these "marine obligate actinomycetes", a clade formed by five Streptomyces strains, closely related to S. xiamenensis (NR044035.1), highlights the importance of studying microbial diversity from ocean sediments (Figure 2B). In this clade, strains with identical 16S rRNA sequences not only show different growth requirements, but also differences in the production of bioactive metabolites in their extracts (see below).

To further explore the evolutionary relationships between our strains and the previously reported ones, we inspected strains related to Nocardiopsis prasina, Actinopolymorpha cephalotaxi, Stackebrandtia endophytica, and Streptomyces aculeolatus (Figure 3), given the relevance of some N. prasina enzymes (chitinases and serine protease) in industrial processes [30,31]; the rarity of $A$. cephalotaxi [32] and S. endophytica [33,34], which represent poorly studied species; and the bioactive meroterpenoids produced by $S$. aculeolatus which are compound families with therapeutic and industrial potential $[23,35,36]$ and were previously isolated from the Madeira Archipelago [25,36]. 


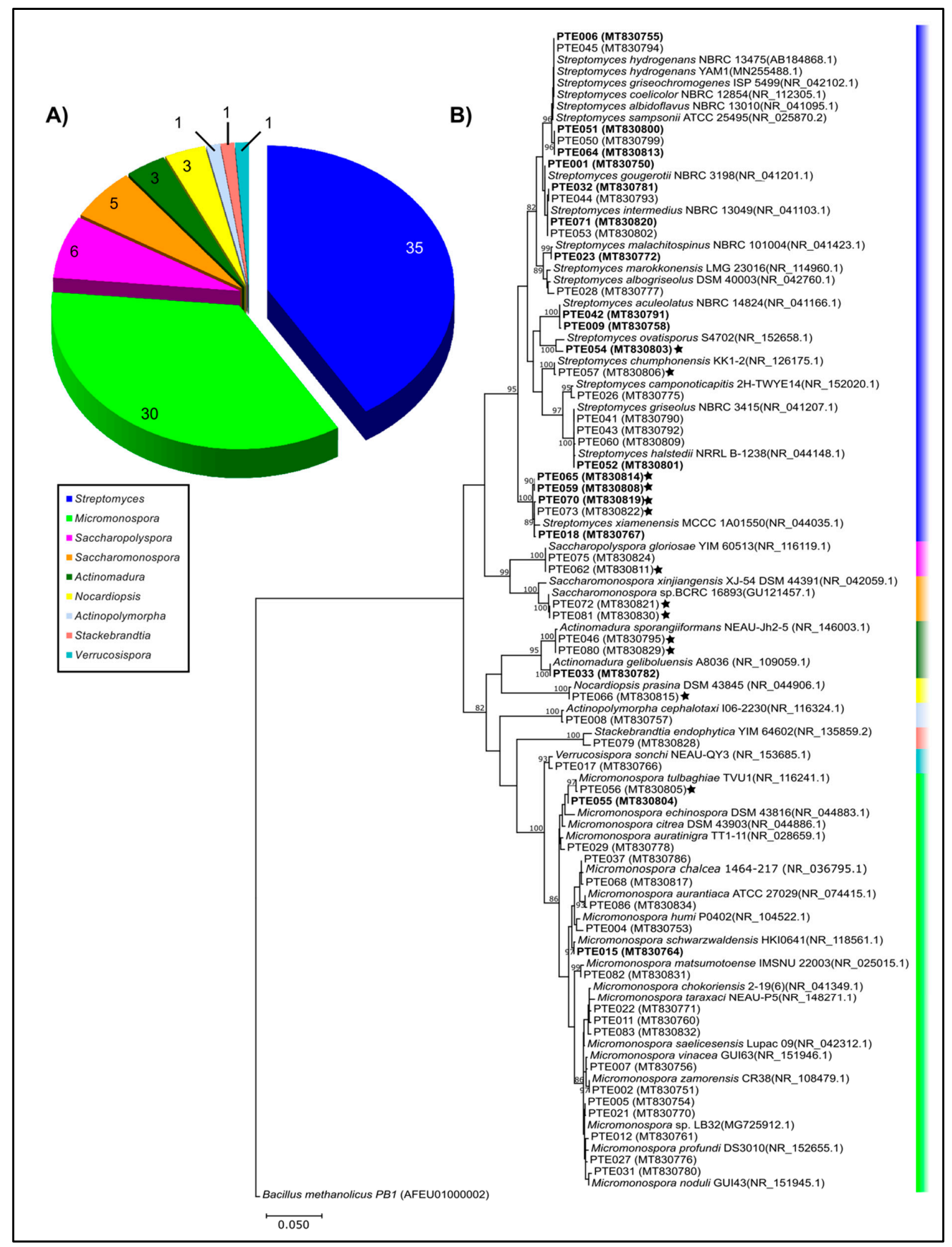

Figure 2. (A) Abundance of actinomycetes genera isolated from Estremadura Spur continental Portugal coastal marine sediments, with indication of the absolute numbers. (B) Maximum likelihood phylogenetic tree of the alignment of the 16S rRNA gene sequences from the 53 representative actinomycetes OTUs from Estremadura Spur, continental Portugal, and the representative sequences of all species retrieved from the GenBank (Table S2). The tree was created using 1000 bootstraps. Nodes above $80 \%$ bootstrap values are shown. GenBank accession numbers are indicated after the sequence name. All PTE numbers refer to internal reference collection codes. Stars symbol represent the strains with seawater requirement for growth. Bioactive PTEs strains are shown in bold. Bacillus methanolicus was used as outgroup. 

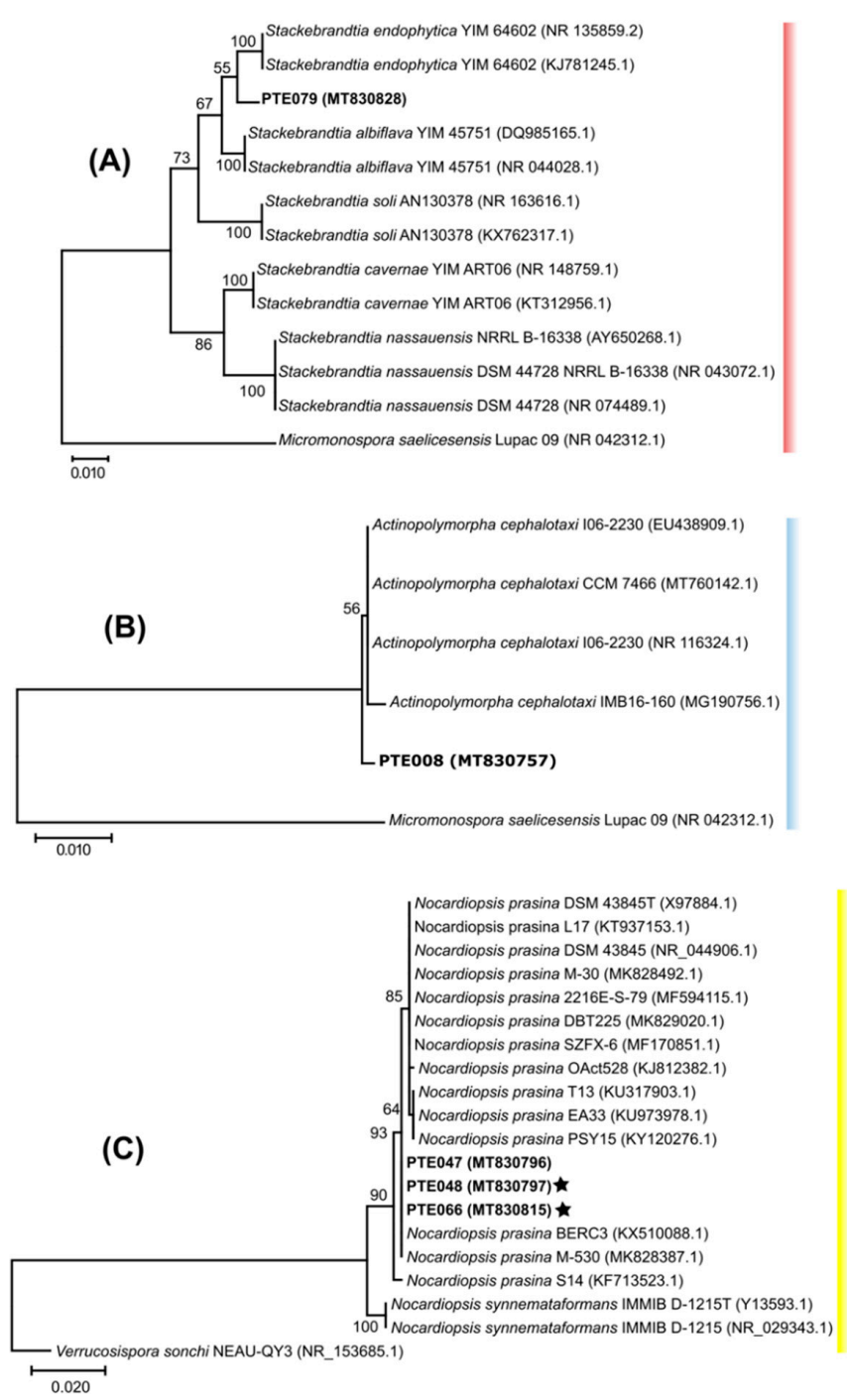

(D) Streptomyces aculeolatus PTM-081 (KP869061.1) Streptomyces aculeolatus PTM-398 (KP869063.1) Streptomyces aculeolatus PTM-420 (KP869064.1) Sireptomy ces aculeol
PTE042 (MT830791)

Streptomyces aculeolatus PTM-029 (KP869059.1) - Streptomyces synnematoformans S155 (EF121313.1) 8 Streptomyces aculeolatus PTM-346 (KP869060.1) 100 Streptomyces sp. MAR4 CNR927 PL04 (DQ448786.1) Streptomyces xinghaiensis S187 (NR_116059.1)

Figure 3. Maximum likelihood phylogenetic tree reconstruction of the alignments of the 16S rRNA gene for four different actinomycetes species from the Estremadura Spur, continental Portugal. (A) Stackebrandtia endophytica, (B) Actinopolymorpha cephalotaxi, (C) Nocardiopsis prasina, and (D) Streptomyces aculeolatus. Each alignment was comprised of sequences of the isolates from the respective species found in this study and the sequences of the same species available in GenBank. Trees were created using 1000 bootstraps. Nodes above $50 \%$ bootstrap values are shown. GenBank accession numbers are indicated after the sequence name. All PTE numbers refer to internal reference collection codes. Stars symbol represent the strains with seawater requirement for growth. 
Our results revealed that the isolates PTE-008 (MT830757) and PTE-079 (MT830828) from the Estremadura Spur had a 99\% sequence identity with A. cephalotaxi and S. endophytica, respectively. However, the phylogenetic analysis showed that although these isolates cluster with their nearest neighbors, they clade separately into a different branch (Figure 3A,B), suggesting that they could be novel strains. On the other hand, the Estremadura Spur isolates, identified as N. prasina (PTE-047 MT830796, PTE-048 MT830797 and PTE-066 MT830815) and S. aculeolatus (PTE-009 MT830758 and PTE042 MT830791), had 99\% sequence identity with their BLASTn best hits; the phylogenetic analysis revealed clustering within the same branches of the previously described strains, BERC3 (KX510088.1) and M-530 (MK828387.1) for N. prasina (Figure 3C), and with the Madeira Archipelago isolates PTM-081 (KP869061.1), PTM-129 (KP869062.1), PTM-398 (KP869063.1) and PTM-420 (KP869064.1) for S. aculeolatus (Figure 3D), suggesting they are the same species.

A phylogenetic analysis of the BLASTn nearest neighbors and the isolates from Streptomyces and Micromonospora genera revealed a close phylogenetic relationship of different isolates and BLASTn neighbors named after different species in the GenBank database (Figure S2), a commonly encountered sequence divergence error from these analyses [37-42]. Further phylogenetic analyses with these Estremadura Spur isolates (Figures S3 and S4) confirmed the observed ambiguity of $16 \mathrm{~S}$ rRNA sequence phylogeny; however, the PTE strains were referred to their nearest BLASTn neighbor for further analyses to simplify identification within GenBank strains.

Rarefaction curves for the diversity estimation, together with the richness estimator Chao 1 [43] (Figure S5), suggest that improving cultivation methods and increasing sampling efforts may improve the recovery of actinomycete OTUs in these sediments. When compared to their nearest neighbors from the GenBank database, PTE-074, PTE-078, and PTE-085 shared less than a 99\% similarity in their 16S rRNA sequence identities. However, the metabolomics analyses of these strains showed that the metabolites produced by each of them are either novel or have not been deposited in the GNPS database (see Sections 2.2-2.5). Therefore, these strains could be novel OTUs represented by strains which produce unique secondary metabolites that allow them to inhabit specific niches in this environment, and eventually leads them to become novel actinomycete species. This trait has been observed in different Salinispora species, which can share over $99 \%$ of their $16 \mathrm{~S}$ rRNA gene identity and still produce distinct compounds that allow them to grow in a wide diversity of environments, turning them into different species [44,45]. These results suggest that the uniqueness of the pockmark environment found in the Estremadura Spur influences the diversity of actinomycetes present in it, and it can thus be a source of novel actinomycetes with a high potential for new chemical compounds.

\subsection{The Metabolomics Profile of Actinomycete Extracts}

The metabolic profiling of the actinomycete crude extracts was investigated by an unsupervised principal component analysis (PCA) to evaluate the similarities and differences between the extracts, accessing clustering and trends and identifying outliers. The results obtained from the PCA (Figure 4A) displayed two distinct prevalent groups corresponding to extracts produced by the Micromonospora and Streptomyces genera, highlighted in green and purple, respectively, which overlapped with all the other genera (Figure 4A,B). This clustering is in accordance with the phylogenetic analysis in which these genera are predominant (Figure 2). By removing these predominant groups (Micromonospora and Streptomyces) from the PCA, the overlapping region was cleared (Figure 4C), and four distinct groups were revealed by the extracts of Actinomadura, Nocardiopsis, Saccharomonospora, and Saccharopolyspora, presented in pink, green, blue, and light blue, respectively. The metabolites produced by Stackebrandtia were presented separately from the previous four groups. Interestingly, this clustering highlighted that the strains from these five genera produced distinct chemistry. 

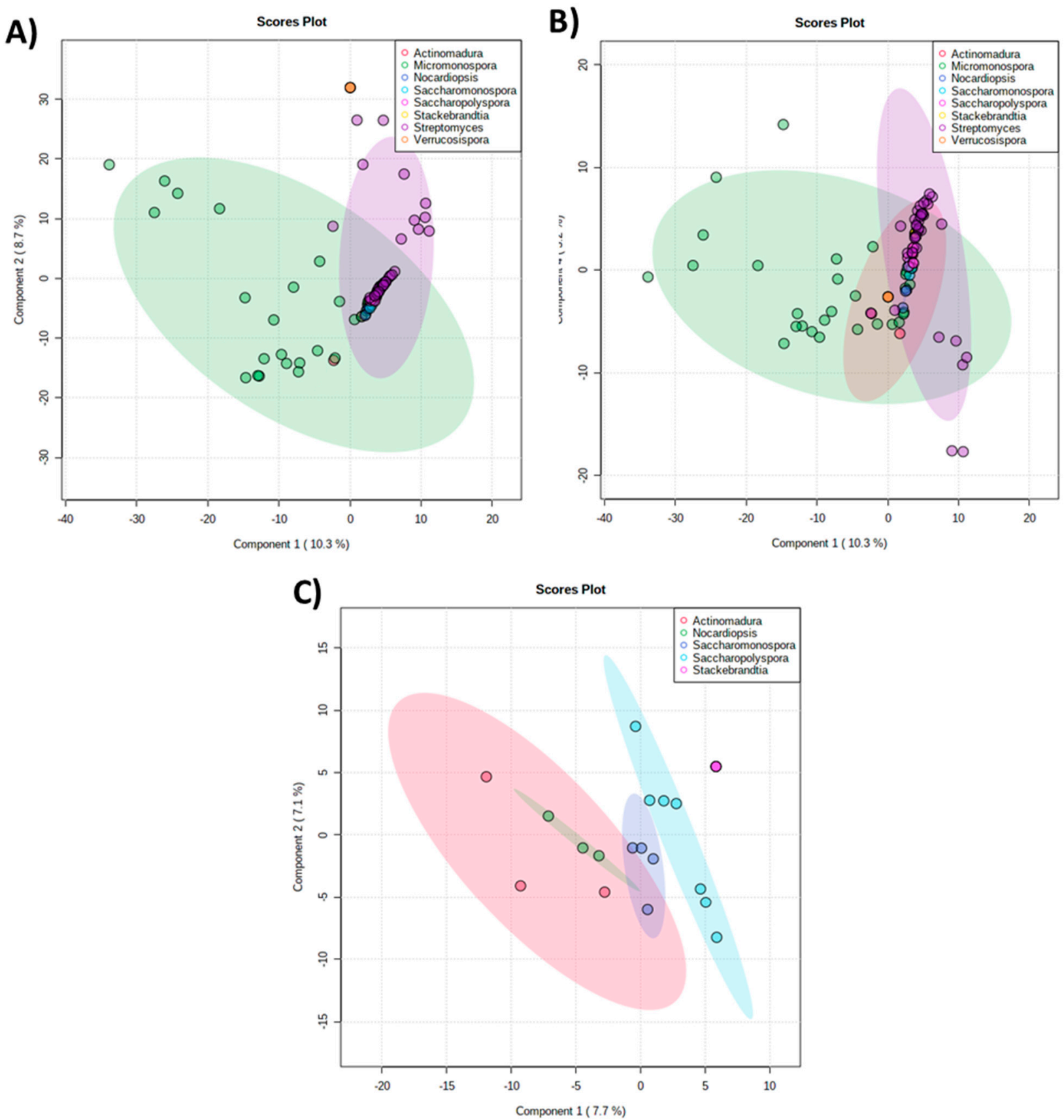

Figure 4. Principal component analysis (PCA). (A) Estremadura Spur actinomycetes crude extracts, indicating two predominant clusters (groups Micromonospora and Streptomyces) formed by chemical similarity. (B) Clustering without Micromonospora and Streptomyces outliners, indicating three main clusters (groups Micromonospora, Streptomyces, and Actinomadura). (C) Clustering without Micromonospora and Streptomyces data, revealing the clusters for Actinomadura, Nocardiopsis, Saccharomonospora, Saccharopolyspora, and Stackebrandtia.

The data shows taxonomy as the strongest parameter that influences the metabolite production, not the habitat or the seawater requirements. Figure 5A displays a trend in which the higher the $m / z$, the lower the polarity. Figure 5 B shows that the $m / z$ in the range of approximately 200-700 $\mathrm{Da}$ are the most abundant in the actinomycetes extracts. 

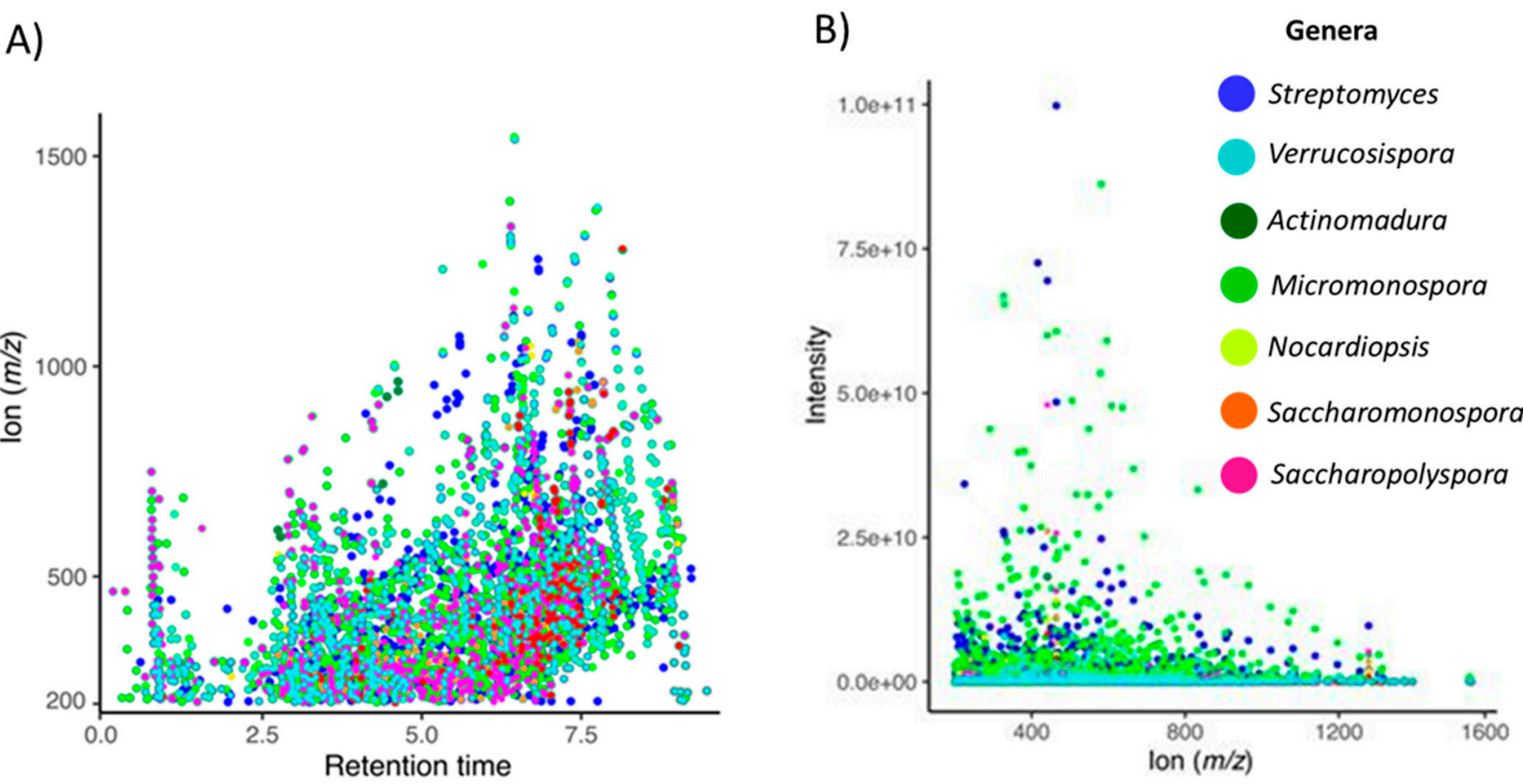

Figure 5. Metabolomics profile of actinomycete crude extracts. (A) Scatter plot showing the distribution of the detected ion as $\mathrm{m} / \mathrm{z}$ according to the elution from the chromatographic system. (B) Scatter plot showing the ions $\mathrm{m} / \mathrm{z}$ with higher abundances. Colors represent the genera of the strains that produced the extracts according to the legend.

\subsection{MS/MS-Based Molecular Networking}

To improve the visualization of the LC-MS/MS data, a molecular network was created in the GNPS platform for the extracts produced by the Estremadura Spur strains (Figure 6) [46,47]. It detected 9025 nodes (ions), of which 392 (approximately $4 \%$ ) were annotated (a spectral match with known compounds), enabling dereplication [47]. PTE-008, the only strain recovered from the Actinopolymorpha genus, did not grow in the used culture conditions, which is why it was left out of the metabolomics profiling analysis and further studies.

Chemical classes that have been previously described [48-53], such as peptides (surugamides, etamycins, and rakicidins), alkaloids (physostigmines), polyketides (piericidins), hybrids from the polyketide synthase (PKS)/non-ribosomal peptide synthase (NRPS) biosynthetic pathway (antimycins), hydroxamate-type siderophores (desferrioxamines), and macrolactams (ikarugamycins) were annotated by the GNPS spectral library (level 2, according to MSI) [50]. Surugamides are cyclic octapeptides with the ability to inhibit cathepsin B, a cysteine peptidase overexpressed in several pathological events such as inflammation and cancer; thus, it has good prospects for cancer treatment $[51,54,55]$.

Antimycins are nine-membered bis-lactones exhibiting antibiotic activity that induce apoptosis and inhibit the mitochondrial electron transport chain from cytochrome $b$ to cytochrome C1 [56-59]. Etamycins are cyclic peptide antibiotics first isolated from Streptomyces sp. $[48,60,61]$. Physostigmines are tricyclic skeleton alkaloids originally isolated from plants [62] that exhibit parasympthomimetic activities and acetylcholinesterase inhibition. Alkaloids belonging to the physostigmine class were first isolated from the marine environment from the bryozoan Flustra foliaceae [63]. Desferrioxamides are cyclic trihydroxamate catecholate-type siderophores that have a higher affinity for the chelation of Fe and is being used to treat thalassemia major patients by chelating the overloaded iron $[64,65]$. Ikarugamycins are polycyclic tetramate macrolactams with diverse biological activities, such as antimicrobial and anti-protozoal activities [66,67]. Piericidines are a well-known class of compounds that have a 4-pyridinol core linked with a methylated 
polyketide side chain with insecticidal, antimicrobial, and antitumor activities [68]. Rakicidins are macrocyclic lipodepsipeptides that exhibit antibacterial and anticancer activities $[69,70]$. Interestingly, except for desferrioxamines, the annotated chemical families are very distinct from the actinomycetes isolated from the Madeira Archipelago, Portugal, studied by our group. We annotated nucleoside derivatives, diketopiperazines, phenazines, peniprequinolones, and desferrioxamines [23] which, as mentioned above, also showed Streptomyces and Micromonospora as the main prevalent genera, highlighting that the Estremadura Spur pockmarks are a very interesting and unique source of actinomycetes, and consequently, metabolites. Conversely, the metabolites annotated from the actinomycetes from the Estremadura Spur exhibited similar chemistry to those obtained from Rocas Atoll, Brazil (a unique atoll in the South Atlantic) to some extent, in which surugamides and antimycins were detected, suggesting a wide distribution of their Streptomyces producers in the Atlantic Ocean [55].

Genera

Streptomyces

Verrucosispora

Actinomadura

Micromonospora

Nocardiopsis

Saccharomonospora

Saccharopolyspora

Stackebrandtia

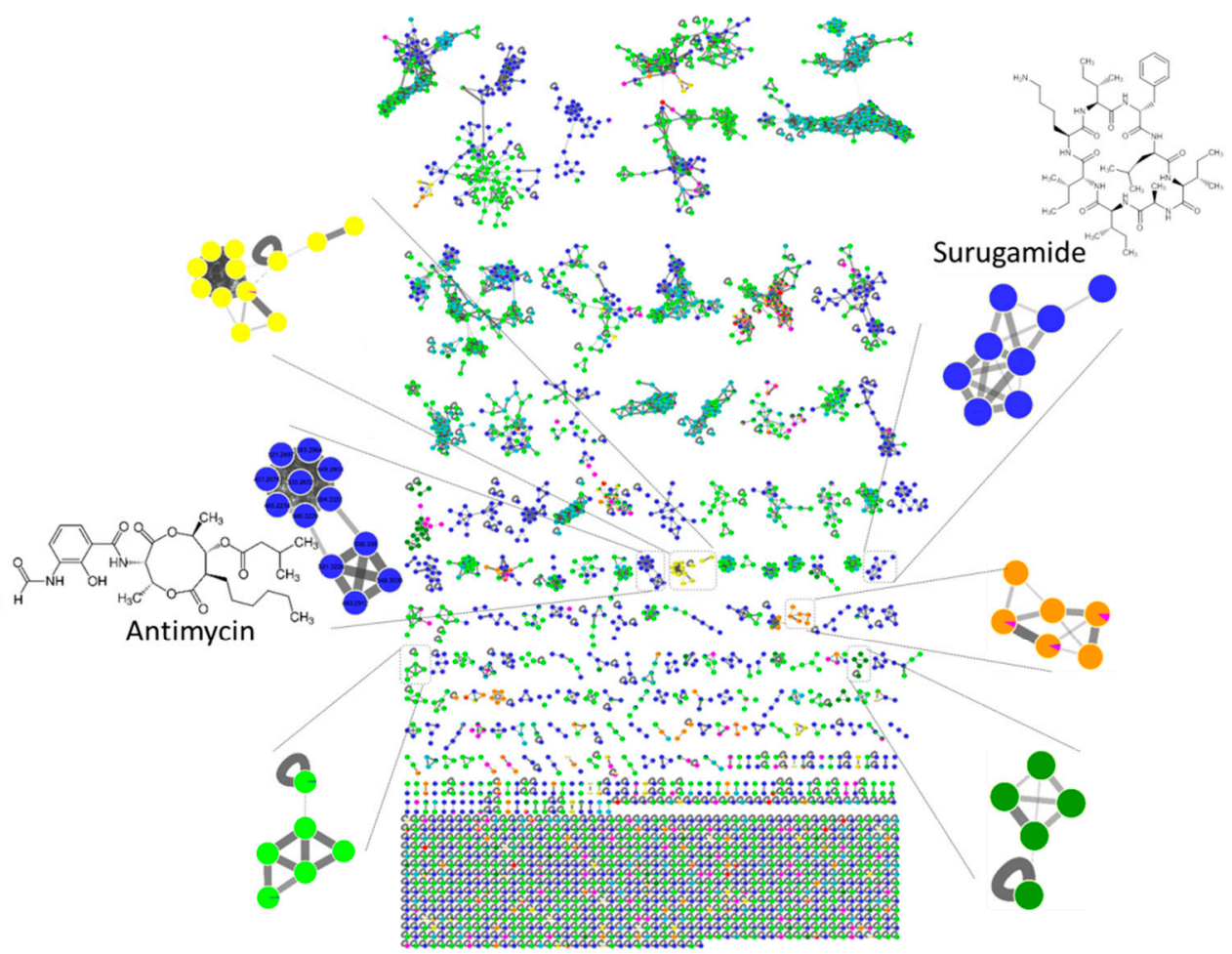

Figure 6. Molecular networking for the Estremadura Spur strains using MS/MS data with a positive ionization mode (ESI+). Nodes represent parent ions, and edge strength indicates the chemical similarity between the MS/MS spectra. Node colors represent the extracts according to the legend. The node size indicates the number of MS/MS spectra. Only clusters containing at least two nodes are shown.

The molecular network allowed the visualization of several molecular families that are produced exclusively by specific taxonomic groups (genus-specific), such as surugamides, antimycins, and etamycins produced by Streptomyces strains, as well as physostigmines, desferrioxamines, ikarugamycins, piericidines, rakicidins, and many others that have not been identified. The MS/MS results revealed that the number of exclusive metabolites produced by the strains obtained from the pockmarks is higher than those obtained from small mound strains (Figure S6A). However, these numbers might not be relevant, as the number of small mound stations and isolated strains is smaller than those from the pockmarks (Table 2 and Table S1). 
Table 2. Diversity and distribution of actinomycetes from the Estremadura Spur, continental Portugal coast, according to the geographic locations. The numbers 1 to 14 in the header correspond to each of the codes of the geographic locations of the sediment collection: 1 (D01PC1), 2 (D01PC3), 3 (PES GR1), 4 (PES GR6), 5 (PES GR9), 6 (PESGR14), 7 (PESGR17), 8 (PESGR20), 9 (PESGR22), 10 (PESGR23), 11 (PESGR24), 12 (PESGR25), 13 (PESGR26), 14 (PESGR27).

\begin{tabular}{ccccccccccccccc}
\hline Stations & $\mathbf{1}$ & $\mathbf{2}$ & $\mathbf{3}$ & $\mathbf{4}$ & $\mathbf{5}$ & $\mathbf{6}$ & $\mathbf{7}$ & $\mathbf{8}$ & $\mathbf{9}$ & $\mathbf{1 0}$ & $\mathbf{1 1}$ & $\mathbf{1 2}$ & $\mathbf{1 3}$ & $\mathbf{1 4}$ \\
\hline OTUs & 3 & 1 & 6 & 3 & 1 & 1 & 10 & 14 & 6 & 11 & 1 & 8 & 2 & 2 \\
$\mathrm{~N}^{\circ}$ of isolates & 5 & 1 & 7 & 4 & 1 & 1 & 16 & 15 & 6 & 16 & 1 & 8 & 2 & 2 \\
$\mathrm{~N}^{\circ}$ of samples & 1 & 1 & 1 & 1 & 1 & 1 & 1 & 1 & 1 & 1 & 1 & 1 & 1 & 1 \\
Isolates/Sample & 5 & 1 & 7 & 4 & 1 & 1 & 16 & 15 & 6 & 16 & 1 & 8 & 2 & 2 \\
Shannon index & 0.50 & 0.00 & 1.55 & 0.56 & 0.00 & 0.00 & 1.99 & 2.25 & 1.79 & 1.67 & 0.00 & 2.08 & 0.69 & 0.69 \\
\hline
\end{tabular}

The produced metabolites are more likely strain-specific than marine-obligate (Figure 5 and Figure S6A,B). Nevertheless, several unknown molecular families have been detected exclusively in seawater-requiring strains (Figure S7), as was the case for Micromonospora saelicesensis PTE-038, Streptomyces ovatisporus PTE-054, Streptomyces chumphonensis PTE-057, Streptomyces xiamenensis PTE-059, Streptomyces chumphonensis PTE-061, Streptomyces xiamenensis PTE-065, Streptomyces xiamenensis PTE-070, Saccharomonospora xinjiangensis PTE-072, Saccharomonospora piscinae PTE-081, and Saccharomonospora xinjiangensis PTE-085.

\subsection{Surugamide, Antimycin, Etamycin, Physostigmine, Desferrioxamine, Ikarugamycin, Piericidine, and Rakicidin Families}

Our results revealed unknown surugamide, antimycin, etamycin, physostigmine, desferrioxamine, ikarugamycin, piericidine, and rakicidin derivatives, suggesting the Estremadura Spur to be a promising source of new compounds for future investigation with prospects that can be applied for medical and biotechnological uses. Surugamide derivatives were found in seven Streptomyces strains: PTE-035, PTE-036, PTE-040, PTE-045, PTE-050, PTE-054, and PTE-064. To date, there are only five surugamides described in the literature [51,71]. The surugamide family contains several unknown derivatives (Figure 7A), thus suggesting that these actinomycetes are a promising source of new compounds to be further investigated. Antimycins were detected in strains PTE-001, PTE-035, PTE-036, PTE-040, PTE-045, PTE-049, PTE-050, and PTE-064 from Streptomyces genera (Figure 7B) and several metabolites detected in these strains are unknown. Etamycin derivatives were detected in the Streptomyces strain PTE-054 (Figure 7C). Comparing the etamycin node data with the literature, we suggest that some of these derivatives might belong to the fijimycin class. Fijimycins are etamycin-class depsipeptides that exhibit antibacterial activity [72] To date, only three fijimycins have been reported [72].

Although originally isolated from the Streptomyces species, in our work, physostigmine derivatives were detected in strains PTE-019, PTE-021, PTE-030, PTE-047, PTE-048, PTE-049, PTE-054, and PTE-066 belonging to Nocardiopsis, Micromonospora and Saccharopolyspora genera (Figure 7D). Desferrioxamine derivatives were detected in strains PTE-007, PTE-030, PTE-031, PTE-055, PTE-061, PTE-075, and PTE-076 from Micromonospora, Streptomyces and Saccharopolyspora genera. Rakicidin derivatives were detected in strains PTE-024, PTE-065, PTE-075, and PTE-076 also belonging to Micromonospora, Streptomyces and Saccharopolyspora genera. Ikarugamycin derivatives were present in numerous strains, such as PTE-018, PTE-019, PTE-033, PTE-034, PTE-038, PTE-046, PTE-053, PTE-054, PTE-059, PTE-060, PTE-061, PTE-063, PTE-064, PTE-065, PTE-066, PTE-067, PTE-068, PTE-071, PTE073, PTE-074, and PTE-085 from Streptomyces, Saccharopolyspora, Micromonospora, Actinomadura, Nocardiopsis, and Saccharomonospora genera. Finally, piericidine derivatives were also present in several strains, namely, PTE-024, PTE-027, PTE-034, PTE-035, PTE-036, PTE-041, PTE-054, PTE-056, PTE-057, PTE-058, PTE-061, and PTE-085 from Streptomyces, Micromonospora, and Saccharomonospora genera. 
Genera

Streptomyces

Verrucosispora

Actinomadura

Micromonospora

Nocardiopsis

Saccharomonospora

Saccharopolyspora

Annotated-spectral library
A

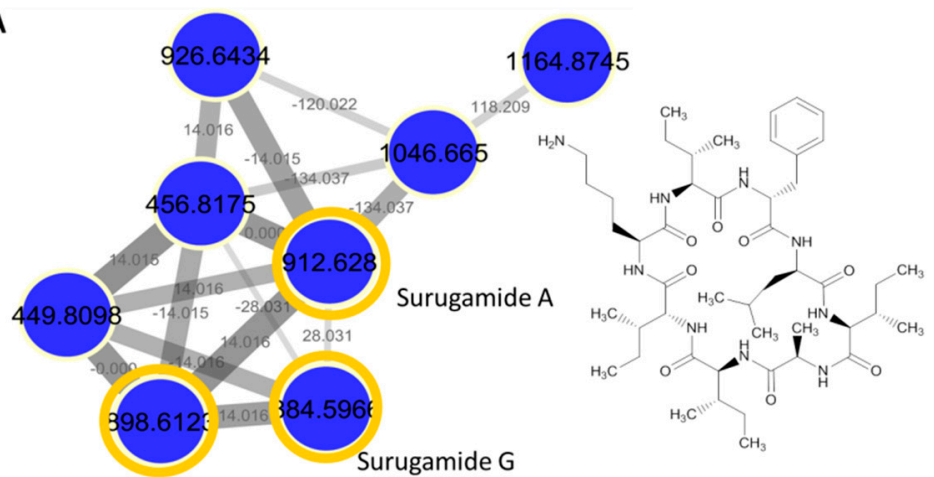

Surugamide $B, C$ or D
B

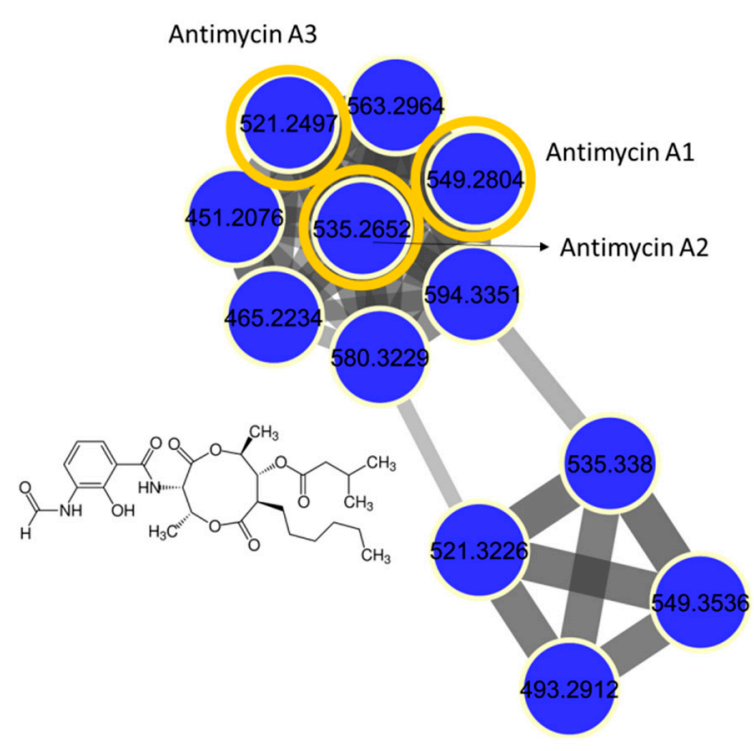

C
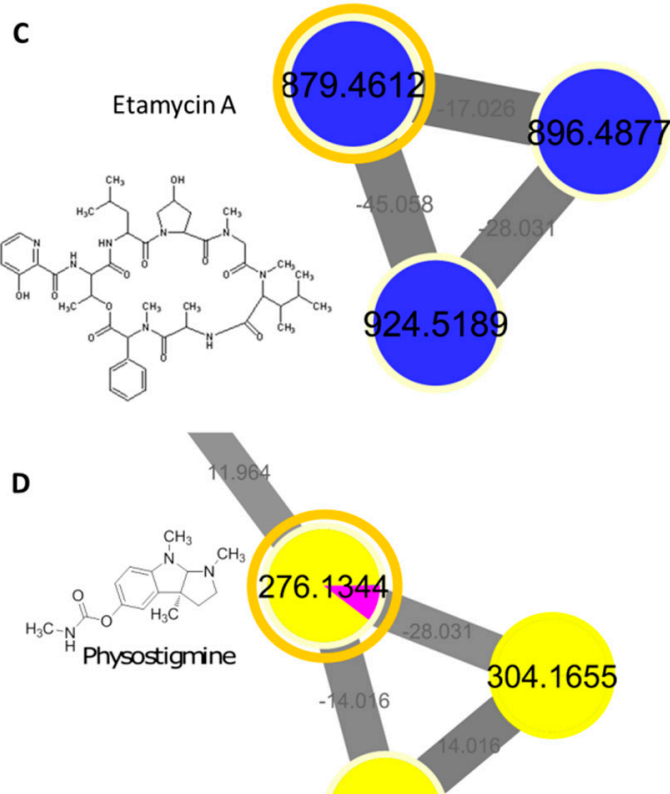

290.15

Figure 7. (A) Cluster from surugamides produced by Streptomyces strains. Nodes represent parent ions, and edge strength indicates the chemical similarity between the MS/MS spectra. Node colors represent the extracts according to the legend. The node size indicates the number of MS/MS spectra. Only clusters containing at least two nodes are shown. (B) Cluster from antimycin derivatives produced by Streptomyces strains. (C) Cluster from etamycin derivatives produced by Streptomyces strains. (D) Cluster from physostigmine derivatives produced by Nocardiopsis strains. The structures are representatives of each molecular family. MS does not detect stereochemistry, except a few particular cases.

Besides the molecular families specifically shown in the Streptomyces and Nocardiopsis strains (Figure 7), the Estremadura Spur actinomycetes revealed numerous other molecular families that were detected in a single genus (i.e., genera-specific) which have not been annotated by the GNPS, as was the case of Streptomyces, Micromonospora, Actinomadura, Saccharopolyspora, and Saccharomonospora. Overall, this clustering is in accordance with the genera grouping observed in the PCA and denotes the high chemical potential of these strains for the discovery of novel secondary metabolites.

\subsection{Qemistree Data Analysis}

Mass spectrometry data of the Estremadura Spur actinomycete extracts was analyzed by Qemistree (Figure 8), a new GNPS analysis tool recently developed by Dorrestein 
et al. [73] in which molecular relationships are represented as a chemical tree based on the hierarchical organization of molecular fingerprints predicted from fragmentation spectra. While the molecular network visualizes closely related molecular families, Qemistree uses fragmentation trees and supervised machine learning from CSI:FingerID [74] to calculate all pairwise chemical relationships, and then visualizes it in the context of sample metadata and molecular annotations that account for the inference of chemical relationships in a dataset. Qemistree representation of the MS/MS data allowed in-silico matching, using CSI:Finger ID (level 3, according to MSI [50]), with fatty acids to the Micromonospora and Streptomyces strains, and macrolactams and prenol lipids to Streptomyces (Figure 8).

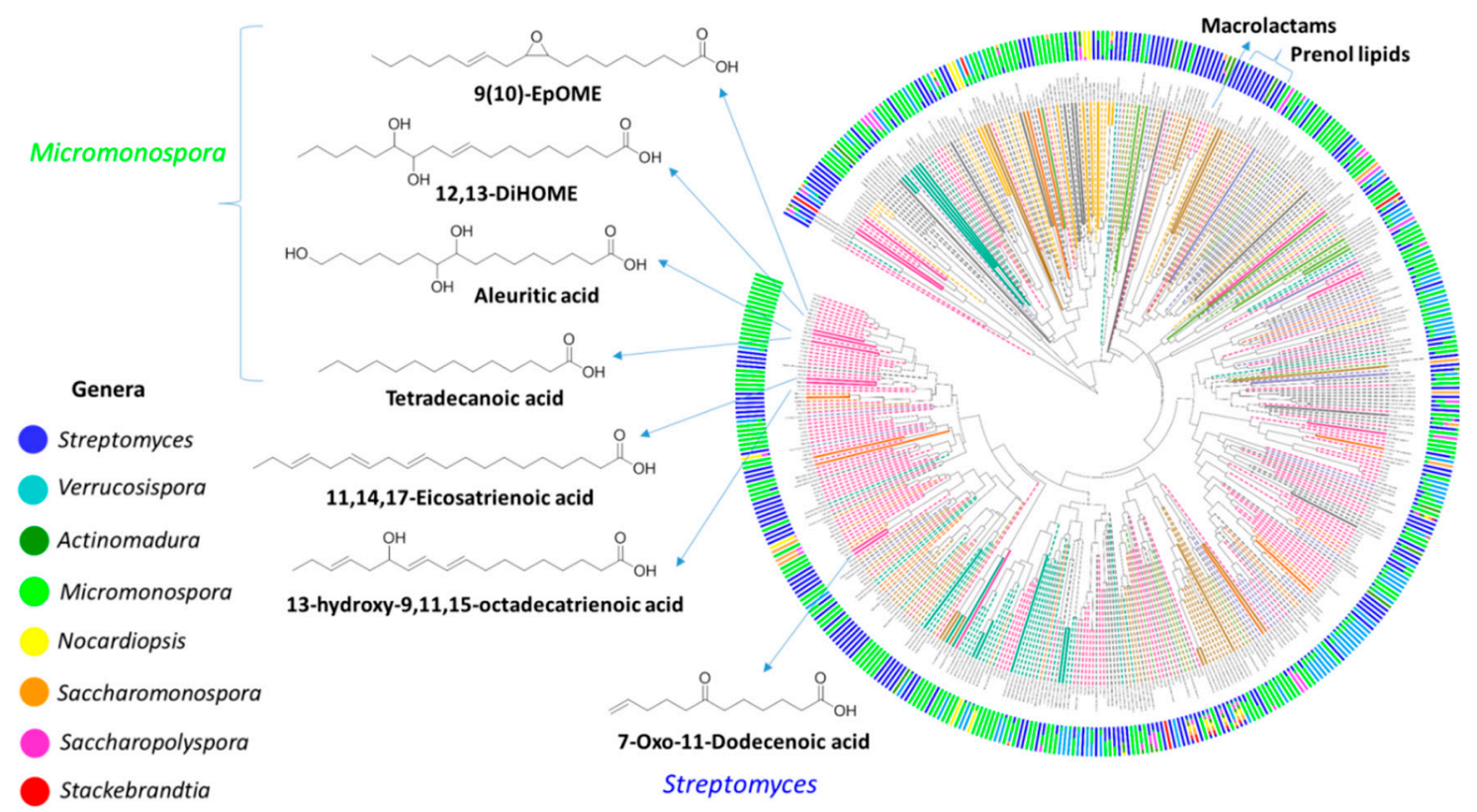

Figure 8. Estremadura Spur actinomycetes Qemistree. Outer ring displays the relative abundance of metabolites stratified by the genera of the strains. Genera colors are according to the legend. Inner ring represents the structural relationships between metabolites establishing a chemical class hierarchy. The presented structures are spectral reference library matches obtained from the GNPS.

Unlike the crude extracts from the Madeira Archipelago and other locations previously studied by our group [23], 66.7\% $(n=84)$ of the Estremadura Spur crude extracts have oil consistency. Qemistree reveals the presence of fatty acids, suggesting that these strains have evolved to produce these chemical compounds in a higher abundance than strains from other locations. Based on these results, a detailed investigation of the Estremadura Spur fatty acids by GC-MS, and the evaluation of their biotechnological potential, is currently ongoing in our lab. From the geological point of view, these results suggest that the Estremadura Spur pockmarks are dormant and not inactive, as initially presumed. Sulfate-reducing bacteria (SRB) involved in the anaerobic oxidation of methane (AOM) produce characteristic fatty acids. These lipidic biomarkers can provide evidence for the role played by archaea and SRB in AOM. Our results suggest that similar traits may occur with actinomycetes [75]. The Qemistree representation also showed that the majority of the chemical classes seemed to act as chemotaxonomic markers, as they presented a genera-specific distribution.

\subsection{The Evaluation of the Actinomycetes Biotechnological Potential}

In order to assess the biotechnological potential of the marine-derived actinomycetes from the Estremadura Spur pockmarks, 84 crude extracts were tested for their antimicrobial activity against three human pathogenic bacteria: methicillin-resistant Staphylococcus aureus (MRSA, COL); methicillin-susceptible Staphylococcus aureus (MSSA, NCTC 8325) and 
Escherichia coli (K12) (Table 3); the human pathogenic yeast Cryptococcus neoformans; and the dermatophytic fungus Trichophyton rubrum (Table 4). The anticancer activity and general toxicity of the extracts were assessed against the human colon carcinoma cell line HCT-116 and the non-cancerous human keratinocyte cell line $\mathrm{HaCaT}$, respectively. Finally, the extracts were evaluated for their cellular antioxidant activities using a $2^{\prime} 7^{\prime}$-dichlorofluorescin diacetate (DCFH-DA) radical on the human keratinocytes (HaCaT) (Table 5).

Table 3. Antimicrobial activity of the marine actinomycetes crude extracts against methicillinresistant Staphylococcus aureus (MRSA, strain COL), methicillin-susceptible Staphylococcus aureus (MSSA, strain NCTC 8325), and Escherichia coli (strain K12). MIC values are in $\mu \mathrm{g} / \mathrm{mL}$. NA—Not Active. — symbol—Not Applicable.

\begin{tabular}{|c|c|c|c|c|c|}
\hline Extract Code & $\begin{array}{c}\text { GenBank Accession } \\
\text { Number }\end{array}$ & $\begin{array}{c}\text { Species } \\
\text { Best Match Identity (\%) in the NCBI } \\
\text { Database }\end{array}$ & MRSA & MSSA & E. coli \\
\hline PTE-006 & MT830755 & Streptomyces griseochromogenes (99\%) & 125 & 125 & NA \\
\hline PTE-009 & MT830758 & Streptomyces aculeolatus (99\%) & 3.9 & 3.9 & NA \\
\hline PTE-010 & MT830759 & Streptomyces griseolus (99\%) & 250 & 250 & NA \\
\hline PTE-015 & MT830764 & Micromonospora schwarzwaldensis (100\%) & NA & NA & 250 \\
\hline PTE-018 & MT830767 & Streptomyces xiamenensis $(99 \%)$ & 250 & 250 & NA \\
\hline PTE-023 & MT830772 & Streptomyces malachitospinus (100\%) & NA & NA & 250 \\
\hline PTE-024 & MT830773 & Micromonospora chalcea $(100 \%)$ & NA & NA & 125 \\
\hline PTE-025 & MT830774 & Micromonospora matsumotoense (99\%) & 62.5 & 125 & 1.9 \\
\hline PTE-032 & MT830781 & Streptomyces intermedius $(100 \%)$ & NA & NA & 125 \\
\hline PTE-033 & MT830782 & Actinomadura geliboluensis (99\%) & 250 & NA & NA \\
\hline PTE-034 & MT830783 & Streptomyces chumphonensis (99\%) & 62.5 & 125 & NA \\
\hline PTE-036 & MT830785 & Streptomyces gougerotii (99\%) & 250 & NA & NA \\
\hline PTE-040 & MT830789 & Streptomyces sampsonii $(100 \%)$ & 250 & NA & NA \\
\hline PTE-042 & MT830791 & Streptomyces aculeolatus (100\%) & NA & 62.5 & NA \\
\hline PTE-049 & MT830798 & Streptomyces intermedius (99\%) & 250 & 62.5 & 250 \\
\hline PTE-051 & MT830800 & Streptomyces sampsonii $(99 \%)$ & NA & NA & 125 \\
\hline PTE-052 & MT830801 & Streptomyces griseolus (100\%) & NA & 250 & 250 \\
\hline PTE-054 & MT830803 & Streptomyces ovatisporus (99\%) & 31.3 & 7.8 & 250 \\
\hline PTE-055 & MT830804 & Micromonospora echinospora $(99 \%)$ & NA & NA & 250 \\
\hline PTE-059 & MT830808 & Streptomyces xiamenensis (99\%) & 62.5 & 125 & NA \\
\hline PTE-063 & MT830812 & Streptomyces xiamenensis (99\%) & 31.3 & 31.3 & NA \\
\hline PTE-064 & MT830813 & Streptomyces sampsonii $(100 \%)$ & NA & NA & 250 \\
\hline PTE-065 & MT830814 & Streptomyces xiamenensis (99\%) & 250 & 250 & 250 \\
\hline PTE-070 & MT830819 & Streptomyces xiamenensis (99\%) & 31.3 & 31.3 & NA \\
\hline PTE-071 & MT830820 & Streptomyces intermedius (99\%) & NA & NA & 250 \\
\hline PTE-077 & MT830826 & Saccharopolyspora gloriosae (99\%) & NA & NA & 250 \\
\hline Vancomycin & - & Positive control & 1.9 & 1.9 & - \\
\hline Tetracycline & - & Positive control & - & - & 3.9 \\
\hline
\end{tabular}

Table 4. Results of actinomycetes crude extracts against the human pathogen yeast Cryptococcus neoformans and the dermatophyte Trichophyton rubrum. $\mathrm{IC}_{50}$ values are in $\mu \mathrm{g} / \mathrm{mL}$. - symbolNot Applicable.

\begin{tabular}{ccccc}
\hline Strain/Extract Code & GenBank Accession Number & Species & C. neoformans & T. rubrum \\
\hline PTE-034 & MT830783 & Streptomyces chumphonensis & $>100$ & $59.6 \pm 1.4$ \\
PTE-040 & MT830789 & Streptomyces sampsonii & $12.2 \pm 0.2$ & $58.9 \pm 0.7$ \\
PTE-053 & MT830802 & Streptomyces intermedius & $11.4 \pm 1.9$ & $>100$ \\
Amphotericin B & - & Positive control & $0.06 \pm 0.00$ & - \\
Clotrimazol & - & Positive control & - & $0.04 \pm 0.00$ \\
\hline
\end{tabular}


Table 5. Antioxidant activity (CAA) of the extracts on the human keratinocytes HaCaT cell line. $\mathrm{IC}_{50}$ values are in $\mu \mathrm{g} / \mathrm{mL}$. — symbol-Not Applicable.

\begin{tabular}{cccc}
\hline Strain/Extract Code & GenBank Accession Number & Species & HaCaT \\
\hline PTE-001 & MT830750 & Streptomyces gougerotii & $11.2 \pm 1.4$ \\
PTE-006 & MT830755 & Streptomyces & $69.2 \pm 10.3$ \\
& griseochromogenes & \\
PTE-009 & MT830758 & Streptomyces & $5.0 \pm 0.6$ \\
PTE-040 & aculeolatus & $11.8 \pm 0.8$ \\
Luteolin & - & Streptomyces sampsonii & $4.0 \pm 0.1$ \\
\hline
\end{tabular}

\subsection{Antibacterial Activity Evaluation}

Twenty-six actinomycetes crude extracts revealed antibacterial activity, although several showed residual activity; 15 against MRSA, 14 against MSSA, and 14 against E. coli (Table 3).

As expected, most extracts that showed growth inhibition activity against the MRSA strain also showed activity against the MSSA strain (12 out of 17 active extracts, $70.6 \%$ ). Interestingly, most extracts that exhibited activity against the Gram-positive bacterium $S$. aureus did not inhibit the growth of the Gram-negative bacterium E. coli; namely, 12 out of the 17 extracts (70.6\%). A reverse behavior was also observed, i.e., with the extracts with anti-E. coli activity, 9 out of the 14 extracts (64.3\%) were inactive against $S$. aureus. These observations suggest that the compounds present in the extracts may predominantly target the bacterial cell wall. The most active extracts were S. aculeolatus (MT830758) that inhibited, equipotently, both MRSA and MSSA strains (MIC value $3.9 \mu \mathrm{g} / \mathrm{mL}$ ) and S. ovatisporus (MT830803), which had four-fold higher activity against MSSA (MIC $7.8 \mu \mathrm{g} / \mathrm{mL}$ ) than MRSA (MIC $31.3 \mu \mathrm{g} / \mathrm{mL}$ ). The remaining extracts with $S$. aureus inhibitory activity had MIC values ranging from 31.3 to $250 \mu \mathrm{g} / \mathrm{mL}$ (Table 3). Strikingly good activity was observed with the Micromonospora matsumotoense (MT830774) extract, which demonstrated the highest activity against the Gram-negative strain E. coli (MIC $1.9 \mu \mathrm{g} / \mathrm{mL}$ ), while all other extracts, as mentioned above, had marginal potency, with MIC values ranging from 125 to $250 \mu \mathrm{g} / \mathrm{mL}$ against this bacterium. Remarkably, the M. matsumotoense extract exhibited an MIC value $(1.9 \mu \mathrm{g} / \mathrm{mL})$ lower than the standard compound tetracycline $(3.9 \mu \mathrm{g} / \mathrm{mL}$ ) (Table 3). Amongst the bioactive strains were the antimycin producing strains, namely, PTE-036, PTE-040, PTE-049, and PTE-064; the etamycin producing strain PTE-054; the ikarugamicin producing strains PTE-018, PTE-033, PTE-034, PTE-054, PTE-059, PTE-063, PTE-064, PTE-065, and PTE-071; the pieridicin producing strains PTE-024, PTE-034, PTE036, and PTE-054; and the rakicidin producing strains PTE-024 and PTE-065. Nevertheless, the majority of the bioactive strains produced metabolites that have not been found in the spectral libraries in the GNPS, highlighting the prospects for the future isolation of novel antibacterial compounds.

\subsection{Antifungal and Antiyeast Activity Evaluations}

Three extracts showed moderate activity against the pathogenic fungus Trichophyton rubrum and the yeast Cryptococcus neoformans. As shown in Table 4, S. sampsoni and $S$. intermedius extracts demonstrated activity against the yeast $C$. neoformans with $\mathrm{IC}_{50}$ values of 12.2 and $11.4 \mu \mathrm{g} / \mathrm{mL}$. The yeast $C$. neoformans is linked mainly to lung infections, meningitis, and encephalitis particularly in immunocompromised patients [76,77]. A low anti-dermatophytic potential was exerted against Trichophyton rubrum by the extracts of S. chumphonensis and S. sampsoni ( $\mathrm{IC}_{50}$ values of 59.6 and $58.9 \mu \mathrm{g} / \mathrm{mL}$, respectively). The dermatophyte fungus, T. rubrum, also found in the skin microbiome, is responsible for athlete's foot, nail infections, ringworm and jock itch [78]. 


\subsection{Anticancer and Cytotoxicity Evaluations}

The Estremadura Spur actinomycetes did not exert anticancer activity against human colon carcinoma (HCT-116) cells at the highest test concentrations $(100 \mu \mathrm{g} / \mathrm{mL})$. Out of 84 extracts, 11 showed low activities against the HCT-116 cells with $20 \%$ to $50 \%$ inhibition rates at $100 \mu \mathrm{g} / \mathrm{mL}$, hence, the $\mathrm{IC}_{50}$ values were not determined. The extracts also lacked toxicity against the human keratinocyte HaCaT cells. Despite the annotation of surugamides and rakicidins with known anticancer activities [51], our anticancer activity results are not very potent, which might be due to the low concentrations of these metabolites in the extracts. Similarly, surugamides were detected mainly in noncytotoxic Streptomyces extracts from Rocas Atoll [55].

\subsection{Antioxidant Activity Evaluations}

Four extracts belonging to the Streptomyces species showed significant antioxidant activities, with $\mathrm{IC}_{50}$ values ranging from 11.2 to $69.2 \mu \mathrm{g} / \mathrm{mL}$ against the $2^{\prime} 7^{\prime}$-dichlorofluorescin diacetate (DCFH-DA) radical on HaCaT cells. Notably, the S. aculeolatus extract exhibited an $\mathrm{IC}_{50}$ value $(5.0 \mu \mathrm{g} / \mathrm{mL})$ in the same magnitude as the standard compound luteolin $\left(\mathrm{IC}_{50} 4.0 \mu \mathrm{g} / \mathrm{mL}\right.$ ) (Table 5).

\section{Materials and Methods}

\subsection{Marine Sediment Collection}

The sediment samples were collected from the Estremadura Spur pockmark field using a Smith McIntyre Grab between 31 May and 5 June 2017. Surface sediment $(0-1 \mathrm{~cm})$ was picked at 14 stations (Table S1) situated at the center of randomly selected pockmarks and the open sediments in proximity to the pockmarks (Figure 1). The distance between stations varied up to $10 \mathrm{~km}$. After collection, the samples were placed in labelled sterile bags (Nasco whirl-pack) and stored at $-20^{\circ} \mathrm{C}$ until further processing.

\subsection{Marine Sediment Inoculation}

All the sediments collected were inoculated onto the surface of the three following agar media: medium 1 (A1), $18 \mathrm{~g}$ of agar, $10 \mathrm{~g}$ of starch, $4 \mathrm{~g}$ of yeast extract, $2 \mathrm{~g}$ of peptone; medium $2\left(\frac{1}{2} \mathrm{~A} 1\right), 18 \mathrm{~g}$ of agar, $5 \mathrm{~g}$ of starch, $2 \mathrm{~g}$ of yeast extract, $1 \mathrm{~g}$ of peptone; and medium 3 (SWA), $18 \mathrm{~g}$ of agar. All media were prepared with filtered seawater and deionized (DI) water in the proportion of 75:25 $(v / v)$, supplemented with the antifungal agent cycloheximide $\left(100 \mu \mathrm{g} \cdot \mathrm{mL}^{-1}\right)$. The inoculation was performed using two methods, heat-shock and drying, as described [23,79]. Briefly, in the first method, approximately $0.5 \mathrm{~g}$ of wet sediment was diluted with $2 \mathrm{~mL}$ of sterile seawater (SSW). Then, the diluted sample was allowed to settle for two minutes, heated to $55^{\circ} \mathrm{C}$ for $6 \mathrm{~min}$, and then $100 \mu \mathrm{L}$ of the resulting solution was spread on the agar plates. In the second method, the sediments were dried overnight in a laminar flow hood. After this period, an autoclaved plug 1 to $2 \mathrm{~cm}$ in diameter was pressed onto the sediment samples and then repeatedly spread onto the surface of the agar plates in a clockwise direction, creating a serial dilution effect. These techniques were performed to reduce the isolation of Gram-negative bacteria and fungi, and also to enrich the slow-growing, spore-forming actinomycetes.

\subsection{Actinomycete Isolation and Quantification}

In order to monitor actinomycete growth, all the previously inoculated agar plates were incubated at $25^{\circ} \mathrm{C}$ and monitored periodically over 6 months. The unicellular bacteria were recognized by the presence of filamentous hyphae and/or by the formation of tough, leathery colonies that adhered to the agar surface [80]. Therefore, for this study, only the mycelium-forming bacteria belonging to the order Actinomycetales were included. For every plate that yielded actinomycete colonies, the total number of colonies observed was counted, and representatives of all morphotypes were obtained in pure culture by their repeated transfer to A1 medium agar plates from a single colony. The pure strains isolated were grouped based on the presence or absence of aerial mycelium, the colony 
size, morphology, the colony color, spore appearance, diffusible pigment production, and the presence or absence of aerial hyphae and the effects of seawater on growth. Eighty-five pure actinomycetes isolates were obtained, which were subsequently cultured in a liquid medium (A1 without agar) and cryopreserved in $10 \%(v / v)$ glycerol at $-80{ }^{\circ} \mathrm{C}$.

\subsection{Seawater Requirement for Growth}

The requirement of seawater for the growth of the 85 actinomycetes was assessed, as described [14,23]. This was accomplished by replacing seawater with DI water in the culture medium and observing the effects on growth through visual monitoring for 6 months. Cells from a well-defined colony were inoculated onto medium A1DI plates (A1 prepared with DI water). Plates were incubated at $25^{\circ} \mathrm{C}$ and, if no growth was observed on the A1DI plate, that strain was determined to require seawater for growth. The seawater obligate strains were replated three times for confirmation.

\subsection{DNA Extraction, 16S rRNA Gene Amplification, and Sequencing}

All strains were inoculated in $4 \mathrm{~mL}$ of medium $\mathrm{A} 1$ and incubated at $25{ }^{\circ} \mathrm{C}$ for 3 to 7 days with agitation $(200 \mathrm{rpm})$. Total DNA was extracted using the Wizard Genomic DNA Purification Kit (Promega, Madison, WI, USA) as described by the manufacturer, with some adjustments, as described $[23,36,80]$. The $16 \mathrm{~S}$ rRNA gene was amplified using the primers FC27 (5'-AGAGTTTGATCCTGGCTCAG-3'), RC1492 (5'-TACGGCTACCTTGTTACGACTT$3^{\prime}$ ) [14,80,81], and NZYTaq II DNA polymerase (NZYtech, Lisbon, Portugal). The PCR products were purified using the NZYGelpure PCR clean-up kit (NZYtech) and were sequenced by the Sanger method using the primers described above at STAB VIDA (https: / / www.stabvida.com, accessed on 20 July 2021), where the ABI BigDye ${ }^{\circledR}$ Terminator v3.1 Cycle Sequencing Kit was used.

\subsection{Taxonomic Classification}

The 16S rRNA gene sequencing chromatograms were reviewed and edited with 4Peaks 1.8 (Nucleobytes B.V.). Consensus sequences for each forward/reverse pair were created in Jalview 2.11.1.0 [82] using the multi-sequence aligner MAFFT [83]. Each consensus sequence was compared to the EzTaxon database [84] with the 16S-based ID tool (on 10 July 2020), and to the NCBI (GenBank) rRNA/ITS database with the BLASTn algorithm [85] (on 16 July 2020). When the best hits of the two database searches corresponded to the same species, considering a threshold of $99 \%$ sequence identity, the isolate was taxonomically identified. If both methods differed in their species classification, a further phylogenetic analysis was used to clarify the isolate's species description (see the next section). For that, the representative 16S rRNA gene sequence of each of the species obtained in the best hits of both database searches were retrieved from NCBI (Table S2).

\subsection{Phylogenetic Analyses}

For the phylogenetic analysis, the consensus sequence of each isolate and the representative sequences of each of the species identified from the best hits of the searches in the EzTaxon and NCBI databases (Table S2) were aligned with the online version of MAFFT (https://mafft.cbrc.jp/alignment/server/, accessed on 23 September 2021) using the G-INS-i interactive refinement method. The multi-sequence alignment was trimmed at $5^{\prime}$ and $3^{\prime}$ to compensate for different sequence sizes, leaving sequences of $1000 \mathrm{bp}$ for further analyses. MEGAX 10.1.7 software (http:/ / www.megasoftware.net, accessed on 23 September 2021) [86,87] was used to infer the best DNA substitution model for each trimmed multi-sequence alignment. The model with the lowest BIC (Bayesian Information Criterion) score was used for further phylogenetic analyses [88]. A maximum likelihood tree reconstruction of the trimmed multi-sequence alignment was performed with the same program. Bootstrap coefficients were calculated for 1000 replicates. Bacillus methanolicus PB1(AFEU01000002) was used as outgroup. 


\subsection{Operational Taxonomic Units (OTUs) Groupings}

Operational taxonomic units (OTUs) were defined for the $16 \mathrm{~S}$ rRNA gene sequences of the cultivated actinomycetes using the tools available in MOTHUR v2.13.3 (http:/ / www. mothur.org/, accessed on 25 July 2021) [89] using the default parameters, except when mentioned otherwise. Briefly, these sequences were aligned to the Greengenes-formatted database (available at https:/ / mothur.org/wiki/alignment_database/ accessed on 25 July 2021) using the align.seqs function. The summary.seqs function was used to obtain the summary statistics of the sequence collection. All the sequences reported as problematic were then removed with the screen.seqs function, and the alignment was trimmed with filter.seqs. A phylip-formatted distance matrix of the trimmed multi-sequence alignment was obtained with dist.seqs. Finally, the cluster.classic function, considering an average neighbor algorithm [89], was used to create the OTUs at a $97 \%$ identity threshold. A representative sequence for each OTU was obtained with the get.oturep command.

\subsection{Rarefaction and the Diversity Estimation Analysis}

The rarefaction analysis and the diversity estimation of the actinomycete sequences were calculated using a nonparametric richness estimator, Chao 1 in MOTHUR using the rarefaction.single command, as described by $[90,91]$. This command generated intra-sample rarefaction curves using a resampling without replacement approach. Rarefaction curves provide a way of comparing the richness observed in different samples [89]. The Shannon index diversity is commonly used in bacterial diversity measurements based on operational taxonomic units and provides more inference about the community composition than simple species richness or evenness does [92].

\subsection{Novel OTU Determination}

A representative strain of each OTU was compared to type strains present in the EzTaxon database [84] for 16S rRNA sequence similarity. As described in [23], if a given sequence had less than a $98 \%$ sequence similarity to the nearest type strain, all the strains in that OTU have to be compared to the type strain in order to determine if the whole OTU could be considered novel.

\subsection{Crude Extract Preparation}

The 85 isolated actinomycete strains were cultured under identical growth conditions as described [23]. Seed cultures of $20 \mathrm{~mL}$ in $100 \mathrm{~mL}$ flasks with the medium A1 were grown for 7 days prior to transfer. Each strain was inoculated in $1 \mathrm{~L}$ of medium A1 with shaking at $220 \mathrm{rpm}$ at $30^{\circ} \mathrm{C}$ for 7 days. The culture broth was extracted with EtOAc and the organic layer was concentrated to dryness under vacuum. PTE-008 Actinopolymorpha cephalotaxi was the only strain that did not grow in enough amounts to produce a crude extract under the used conditions. The crude extracts were dissolved in $\mathrm{MeOH}$ at $2 \mathrm{mg} \cdot \mathrm{mL}^{-1}$ concentration for LC-MS/MS analyses and dissolved in DMSO at $10 \mathrm{mg} \cdot \mathrm{mL}^{-1}$ concentration for bioactivity screening.

\subsection{Untargeted Metabolomic Fingerprint by LC-MS/MS}

All samples except the PTE-008 crude extract were injected into a Vanquish UHPLC system coupled to a Q-Exactive orbitrap mass spectrometer (Thermo Fisher Scientific, Bremen, Germany), according to [93]. The chromatographic separation occurred in a C18 porous core column (Kinetex C18, $50 \times 2 \mathrm{~mm}, 1.8$ um particle size, 100 A pore size, Phenomenex, Torrance, CA, USA) kept at $30^{\circ} \mathrm{C}$. The mobile phase consisted of solvent $\mathrm{A}$, $\mathrm{H}_{2} \mathrm{O}+0.1 \%$ formic acid (FA), and solvent $\mathrm{B}$, acetonitrile $(\mathrm{ACN})+0.1 \% \mathrm{FA}$, with a flow rate of $0.150 \mathrm{~mL} / \mathrm{min}$. Five $\mu \mathrm{L}$ of the sample was injected and eluted with the following linear gradients: $0.0-4.0 \mathrm{~min}$ at $5-50 \%$ of $\mathrm{B}, 4.0-5.0 \mathrm{~min}$ at $50-99 \%$ of $\mathrm{B}$, followed by a $2 \mathrm{~min}$ washout phase at $99 \% \mathrm{~B}$ and a $3 \mathrm{~min}$ re-equilibration phase at $5 \% \mathrm{~B}(\operatorname{method} 1)$, or $0-0.5 \mathrm{~min}$ at $5 \%$ of $B, 0.5-9$ min at $5-100 \%$ of $B$, followed by a 2 min washout phase at $99 \%$ B and 
a 5 min re-equilibration phase at $5 \%$ B. MS/MS data was acquired with data dependent acquisition (DDA) performed in the positive mode.

Electrospray ionization (ESI) parameters were set to $53 \mathrm{~L} / \mathrm{min}$ sheath gas flow, $14 \mathrm{~L} / \mathrm{min}$ auxiliary gas flow, $0 \mathrm{~L} / \mathrm{min}$ sweep gas flow, and $400{ }^{\circ} \mathrm{C}$ auxiliary gas temperature. The spray voltage was set to $3.5 \mathrm{kV}$, and the inlet capillary at $320^{\circ} \mathrm{C}$ and $50 \mathrm{~V} \mathrm{~S}$ lens levels were applied. The MS scan range was set to $200-2000 \mathrm{~m} / z$ with a resolution at $m / z 200\left(\mathbf{R}_{m / z} 200\right)$ of 35,000 with one micro scan. The maximum ion injection time was set to $100 \mathrm{~ms}$ with an automated gain control (AGC) target of 5E5. Up to $5 \mathrm{MS} / \mathrm{MS}$ spectra per MS1 survey scan were recorded in DDA mode with $\mathrm{R}_{m / z} 200$ of 17,500 with one micro-scan. The maximum ion injection time for MS/MS scans was set to $100 \mathrm{~ms}$ with an AGC target of 5E5 ions. The MS/MS precursor isolation window was set to $\mathrm{m} / \mathrm{z} 1$. The normalized collision energy was set to a stepwise increase from $20 \%$, to $30 \%$, to $40 \%$ with $z=1$ as the default charge state. MS/MS scans were triggered at the apex of the chromatographic peaks within 2 to $15 \mathrm{~s}$ from their first occurrence. Dynamic precursor exclusion was set to $5 \mathrm{~s}$. Ions with unassigned charge states were excluded from MS/MS acquisition as well as isotope peaks.

\subsection{Classical Molecular Networks}

A molecular network was created using the online workflow (https://ccms-ucsd. github.io/GNPSDocumentation/, accessed on 23 September 2021) on the GNPS website (http://gnps.ucsd.edu accessed on 23 September 2021). The data was filtered by removing all MS/MS fragment ions within +/ - 17 Da of the precursor $m / z$. MS/MS spectra were window filtered by choosing only the top six fragment ions in the $+/-50$ Da window throughout the spectrum. The precursor ion mass tolerance was set to $0.02 \mathrm{Da}$ with a MS/MS fragment ion tolerance of $0.02 \mathrm{Da}$. A network was then created where the edges were filtered to have a cosine score above 0.65 and more than five matched peaks. The 0.65 threshold was used for a more sensitive connectivity of the network. Furthermore, the edges between two nodes were kept in the network if each of the nodes appeared in each other's respective top ten most similar nodes. Finally, the maximum size of a molecular family was set to 100 , and the lowest scoring edges were removed from molecular families until the molecular family size was below this threshold. The spectra in the network were then searched against the GNPS' spectral libraries. The library spectra were filtered in the same manner as the input data. All matches kept between the network spectra and the library spectra were required to have a score above 0.65 and at least five matched peaks.

\subsection{The LC-MS/MS Data Process for Qemistree}

The raw data was converted to a .mzXML format using MSConvert (part of ProteoWizard version 2.1.x, GitHub, San Francisco, CA, USA) [94,95]. For feature detection, the data were processed with MZmine2 $2.51[96,97]$ using the following parameters: a MS1 noise level of $8.0 \times 10^{5}$, and a MS2 noise level of $1.0 \times 10^{3}$. Chromatograms were built with the ADAP chromatogram builder [98] module with the following parameters: "Min group size in \# of scans" = 2; "Group intensity threshold" $=8.0 \times 10^{5}$, "Min highest intensity" $=5.0 \times 10^{5}$; and "maximum $\mathrm{m} / z$ tolerance" $=10 \mathrm{ppm}$. The built chromatograms were deconvoluted using the ADAP (Wavelets) module, and the following parameters were used: a "S/N threshold" of 10; a "min feature height" of $8.5 \times 10^{5}$; a "coefficient/area threshold" of 30; a "Peak duration range" of 0.01-2.0 min; and a "RT wavelet range" of 0.01-0.2 s. The fragmentation spectra were paired to the deconvoluted peaks using $0.05 \mathrm{Da}$ and 0.2 min windows. The LC-MS features (isotopologues, adducts, and in-source fragments) were annotated using the peak grouping module with the following parameters: "deisotope" $=$ true, $m / z$ tolerance at $10 \mathrm{ppm}$, retention time tolerance at $0.2 \mathrm{~min}$, and a max. charge of 3 . The features were aligned with the join aligner module using the following parameters: $7 \mathrm{ppm}$ tolerance, weight for $\mathrm{m} / z$ of 75.0 , a retention time tolerance of $0.2 \mathrm{~min}$, and a weight for RT of 25.0. Finally, the feature table was exported as a .CSV and the 
spectral data as a .MGF and a SIRIUS file. Using the GNPS export module for further processing, only MS ${ }^{1}$ peaks that had a MS ${ }^{2}$ spectrum were considered (GNPS filter).

The .MGF, the features intensity (.csv), and the SIRIUS files were uploaded to the GNPS [47] and analyzed with the feature-based molecular network workflow (https:/ / ccms-ucsd.github.io/GNPSDocumentation/featurebasedmolecularnetworking/ accessed on 23 September 2021). Spectral library matching was performed against the public spectral library. Molecular features in the form of MS/MS spectra were putatively identified using MS2-based spectral library matches based on the cosine score similarity (above 0.7) and a minimum number of shared peaks (6). The parameters and results can be consulted at the following address: https://gnps.ucsd.edu/ProteoSAFe/status.jsp?task=401f1ece6 $7 d c 449 f 99 c d c 43 a 7308 b 543$ accessed on 23 September 2021. The results were subsequently visualized in Cytoscape 3.6 [99]. The MN was colored by genus: Actinomadura (dark green), Micromonospora (light green), Nocardiopsis (yellow), Saccharomonospora (orange), Saccharopolyspora (pink), Streptomyces (dark blue), and Verrucosispora (light blue).

The Qemistree [73], a computing tree-based approach, was generated in the GNPS and the resulting chemical hierarchy was explored in iTOL [100].

\subsection{Bacterial Growth Inhibition Assays}

The antibacterial activity of the crude extracts was evaluated by performing growth inhibition assays for two strains of the Gram-positive human opportunistic pathogen S. aureus, namely, the methicillin-resistant S. aureus strain COL (MRSA) and the methicillinsensitive S. aureus strain NCTC8325-4 (MSSA), as well as against the Gram-negative bacterium Escherichia coli strain K12. The S. aureus strains were grown in tryptic soy broth (TSB; Becton Dickinson, Germany), and E. coli in Lysogeny broth (NZYtech), at $37^{\circ} \mathrm{C}$.

The assays were performed in 96-well polystyrene flat bottom microplates (Nunclon Delta Surface, Thermo Scientific, Roskilde, Denmark). Bacterial overnight cultures were diluted to an optical density (OD600nm) of 0.04-0.06 and were incubated statically in the presence of different concentrations of each crude extract, solubilized in DMSO. All cultures were two-fold serially diluted, resulting in final concentrations of the extracts ranging from 250 to $1.95 \mu \mathrm{g} / \mathrm{mL}$. After $24 \mathrm{~h}$ of incubation at $37^{\circ} \mathrm{C}$, the minimal inhibitory concentration (MIC) value was determined by visual inspection and by a spectrophotometric analysis. The active crude extracts were re-tested for results confirmation. The resulting values were compared with the positive control (vancomycin for MRSA and MSSA, and tetracycline for E. coli K12), a DMSO solvent control, and a negative control (no extract) on the same plate. All assays were performed in triplicate.

\subsection{Antiyeast and Antifungal Assays}

Crude extracts were tested against the human pathogen yeast Cryptococcus neoformans (DSM 6973, Leibniz Institute DSMZ-German Collection of Microorganisms and Cell Cultures, Braunschweig, Germany) and the dermatophyte Trichophyton rubrum (I/95, patient isolate from university clinic of dermatology, Prof. Brasch, Kiel, Germany).

C. neoformans was cultivated in a M186 medium ( $1 \%$ glucose, $0.5 \%$ peptone from soymeal, $0.3 \%$ malt extract, and a $0.3 \%$ yeast extract). An overnight culture of $C$. neoformans $\left(28{ }^{\circ} \mathrm{C}\right.$ and $\left.160 \mathrm{rpm}\right)$ was prepared and diluted to an optical density $(600 \mathrm{~nm})$ of 0.03 . The cultivation of T. rubrum took place on a GPY agar $(0.1 \%$ glucose, $0.05 \%$ peptone, $0.01 \%$ yeast extract, and $1.5 \%$ agar, at a $\mathrm{pH}$ of $7.2-7.4$ ) for two weeks. The spores of the fungus were removed and dissolved in a liquid M186 medium ( $1 \%$ glucose, $0.5 \%$ soy peptone, 0.3 yeast extract, and $0.3 \%$ malt extract) and the concentration was determined with a counting cell chamber. The spore solution was diluted to a final concentration of $5 \times 10^{4}$ spores $/ \mathrm{mL}$ in the M186 medium. The extracts $(10 \mathrm{mg} / \mathrm{mL}$ DMSO stock solution) were transferred into a 96-well microtiter plate in duplicate and $200 \mu \mathrm{L}$ of the cell suspension cultures were added to each well. The final assay concentration of samples was $100 \mu \mathrm{g} / \mathrm{mL}$. The inoculated microplates were incubated for $7 \mathrm{~h}$ at $28^{\circ} \mathrm{C}$ and at $200 \mathrm{rpm}$ for $\mathrm{C}$. neoformans, and $72 \mathrm{~h}$ at $28{ }^{\circ} \mathrm{C}$ and at $120 \mathrm{rpm}$ for T. rubrum. To detect the inhibitory 
effect of the extracts against $C$. neoformans and T. rubrum, the optical density at $600 \mathrm{~nm}$ after the incubation time was recorded using the microplate reader (Tecan Infinite 200). The resulting values were compared with positive controls (amphotericin B for C. neoformans and clotrimazol for T. rubrum) and a negative control (no extract) on the same plate. For $\mathrm{IC}_{50}$ determination, a dilution series was prepared and the $\mathrm{IC}_{50}$ value was calculated using Excel as the concentration that showed a 50\% inhibition of viability on the basis of a negative control.

\subsection{Cytotoxic and Anticancer Assays}

The actinomycete crude extracts were tested in vitro against two human cell lines: the colon carcinoma cell line HCT-116 (DSMZ, Braunschweig, Germany) and the non-cancerous human keratinocyte line HaCaT (CLS, Eppelheim, Germany) at a final concentration of $100 \mu \mathrm{g} / \mathrm{mL}$. HaCaT cells were cultivated in a RPMI medium (Life Technologies, Darmstadt, Germany) and HCT-116 cells in a DMEM medium (Life Technologies), supplemented with $4.5 \mathrm{~g} / \mathrm{L}$ D-Glucose and $110 \mathrm{mg} / \mathrm{L}$ sodium pyruvate. All media were supplemented with L-Glutamine, 10\% fetal bovine serum (FBS, Life Technologies), $100 \mathrm{U} / \mathrm{mL}$ penicillin, and $100 \mathrm{mg} / \mathrm{mL}$ streptomycin (P/S, Life Technologies). The cultures were maintained at $37^{\circ} \mathrm{C}$ under a humidified atmosphere and $5 \% \mathrm{CO}_{2}$. The cell lines were transferred every 3 or 4 days. For the experimental procedure, the cells were seeded in 96-well-plates at a concentration of 10,000 cells per well. After $24 \mathrm{~h}$ of incubation, the medium was removed from the cells and $100 \mu \mathrm{L}$ of the fresh medium containing the test samples was added. Plates were cultured at $37^{\circ} \mathrm{C}$ and $5 \% \mathrm{CO}_{2}$ for $24 \mathrm{~h}$. Each sample was prepared in triplicate. Doxorubicin $(50 \mu \mathrm{g} / \mathrm{mL})$, as a standard therapeutic drug, was used as positive control and a growth medium was used as negative control. The anticancer activity was evaluated by monitoring the metabolic activity using the CellTiterBlue Cell Viability Assay (Promega, Mannheim, Germany). Briefly, $20 \mu \mathrm{L}$ of the CellTiterBlue reagent was added to each well and incubated for $2 \mathrm{~h}$. Afterwards, the assay was performed according to the manufacturer's instructions and measured using the microplate reader Tecan Infinite M200 at an excitation of $560 \mathrm{~nm}$ and an emission of $590 \mathrm{~nm}$. The percentage of inhibition was calculated by comparing the positive control and negative control (no extract) on the same plate. A dilution series was prepared and the $\mathrm{IC}_{50}$ value was calculated by Excel as the concentration that showed a $50 \%$ inhibition of viability on the basis of a negative control (growth medium).

\subsection{The Cellular Antioxidant Activity (CAA) Assay}

The antioxidant activity of the crude extracts against the $2^{\prime} 7^{\prime}$-dichlorofluorescin diacetate (DCFH-DA) radical was evaluated by measuring the cellular antioxidant activity (CAA) on the human keratinocytes HaCaT. HaCaT cells were seeded at a density of 100,000 cells/well and incubated overnight at $37^{\circ} \mathrm{C}$ under a humidified atmosphere and $5 \% \mathrm{CO}_{2}$. Cells were then incubated with DCFH-DA (2'7'-dichlorofluorescin diacetate; Sigma, Burlington, MA, USA) (a final concentration of $25 \mu \mathrm{M}$ ) and the test samples (a final concentration of $100 \mu \mathrm{g} / \mathrm{mL}$ ) in duplicate for $1 \mathrm{~h}$. Luteolin (final concentrations of $100 \mu \mathrm{M})$ was used as positive control. After incubation, $600 \mu \mathrm{M}$ of AAPH $\left(2,2^{\prime}\right.$-azobis(2methylpropionamidine) dihydrochloride, Sigma) was added to all the wells. The plate was immediately placed in the plate reader and the fluorescence was recorded. An excitation of $485 \mathrm{~nm}$ and an emission of $520 \mathrm{~nm}$ were used. The plate was incubated for $10 \mathrm{~min}$ before a second reading. Cells were washed with Hank's balanced salt solution (HBSS, Life Technologies) between the additions of new reagents. The total reaction volume was $100 \mu \mathrm{L}$ (where $50 \mu \mathrm{L}$ was the volume of the test sample). The incubations were at $37^{\circ} \mathrm{C}$ in a humidified atmosphere of $5 \% \mathrm{CO}_{2}$. The resulting values were compared with a positive control and a negative control (no extract) on the same plate. For $\mathrm{IC}_{50}$ determination, a dilution series was prepared and the $\mathrm{IC}_{50}$ value was calculated by Excel as the concentration that showed a $50 \%$ inhibition of viability on the basis of a negative control. 


\section{Conclusions}

This study showed the biotechnological potential of the Estremadura Spur pockmarks actinomycete isolates as a source of antimicrobial and antioxidant agents. It led to the isolation and purification of 85 actinomycetes, 18 of which showed prospects of being marine obligate strains comprised of several seawater requiring strains from genera that have not been reported before and that have the ability to produce exclusive molecular families.

Actinomycetes strains, including "marine obligate" strains, revealed antimicrobial activity against Gram-positive and Gram-negative multidrug resistant bacteria, which allows the prioritization of strains for future compound isolation and structure elucidation. Importantly, sea water requiring strains revealed unknown exclusive molecular family clusters, suggesting that they are a source of novel natural products.

High chemical diversity was revealed in our results. Interestingly, this study highlights the phylogenetically related actinomycetes with different biosynthetic capabilities and shows that the distribution of the majority of the chemical classes was genus-specific, suggesting that the produced metabolites can be used as chemotaxonomic markers.

The Estremadura Spur strains showed a propensity to produce fatty acids, which will lead to an in-depth study of these compounds in the future to evaluate their composition and prospective applications. Moreover, these results suggest that the Estremadura Spur pockmarks may be dormant and not inactive as presumed, as actinomycetes from their sediments have a clear carbon source that allows them to produce fatty acid, suggesting that some oil seeping could still be happening in the area. Overall, this study demonstrates that the regions surrounding the Portuguese coast, in particular the singular Estremadura Spur pockmark field, are rich sources of marine actinomycetes with potential applications for biotechnology.

Supplementary Materials: The following are available online at https:/ /www.mdpi.com/article/ 10.3390/md20010021/s1, Table S1: Estremadura Spur pockmark stations of sediment collection. Table S2: NCBI accession number of the representative 16S rRNA gene sequence of each of the species found as best hit from the search in NCBI rRNA/ITS and EzTaxon databases. Table S3: List of all strains isolated from the Estremadura Spur, continental Portugal coast, including their station, habitat, depth, sea water requirement, and accession number from GenBank (AccessID). Figure S1: Maximum likelihood phylogenetic tree of the alignment of the 16S rRNA gene from all (85) actinomycetes isolates from Estremadura Spur, continental Portugal, and the representative sequences of all species retrieved from the GenBank. Figure S2: Maximum likelihood phylogenetic tree of the alignment of the $16 \mathrm{~S}$ rRNA gene from Streptomyces (A) and Micromonospora (B) isolates from Estremadura Spur, continental Portugal, and the representative sequences of all species of the respective genus retrieved from the GenBank. Figure S3: Maximum likelihood phylogenetic trees of the alignments of the 16S rRNA gene from Streptomyces (A) and Micromonospora (B) isolates from Estremadura Spur, continental Portugal, and the representative sequences of all species of the respective genus retrieved from the GenBank. Figure S4: Maximum likelihood phylogenetic trees of the alignments of the 16S rRNA gene from Streptomyces (A) and Micromonospora (B) isolates retrieved from GenBank. Figure S5: Rarefaction curves for richness (sobs) and estimated richness (chao) using the statistical estimator Chao 1 of isolated marine derived actinomycetes from the Estremadura Spur, continental Portugal. Figure S6: Venn diagram constructed with the ions detected in the crude extracts. Figure S7: Molecular Network for Estremadura Spur actinomycetes strains that require sea water for their growth.

Author Contributions: Conceptualization, S.P.G.; methodology, S.P.G., R.G.S. and D.T.; software, A.P.-A. and A.B.; validation, S.P.G., A.B., R.G.S., D.T. and A.P.-D.; formal analysis, S.P.G., A.P.-A., A.P.-D., A.B., R.G.S., I.R.G. and D.T.; investigation, A.P.-A., A.B., L.L., I.R.G., J.O., J.R.S. and D.P.; bioresources, S.P.G. and C.F.R.; data curation, S.P.G.; writing-original draft preparation, A.P.-A., A.P.-D., A.B., I.R.G., R.G.S., D.T. and S.P.G.; writing-review and editing, S.P.G., A.P.-A., A.P.-D., A.B., D.T., J.R.S., J.O. and D.P.; visualization, all authors; supervision, S.P.G., R.G.S. and D.T.; project administration, S.P.G., R.G.S. and D.T.; funding acquisition, S.P.G., R.G.S., D.T. and C.F.R. All authors have read and agreed to the published version of the manuscript. 
Funding: This work is financed by national funds from FCT-Fundação para a Ciência e a Tecnologia, I.P., in the scope of the project UIDP/04378/2020 of the Research Unit on Applied Molecular Biosciences-UCIBIO and the project LA/P/0140/2020 of the Associate Laboratory Institute for Health and Bioeconomy-i4HB. FCT/MCTES through project grants PTDC/QUIQUI/119116/2010, PTDC/GEO-FIQ/5162/2014 and PTDC/BIA-MIC/31645/2017. Thanks are due to FCT/MCTES for the financial support to CESAM (UIDP/50017/2020+UIDB/50017/2020), through national funds. This publication is based upon work from COST Action CA18238 (Ocean4Biotech), supported by COST (European Cooperation in Science and Technology) programme. APA is thankful for the António Coutinho Prize, awarded supported by Instituto Gulbenkian de Ciência (IGC) under the reference 11/BI-PD/20. LL thanks ERASMUS Mundus for the funding. JRS acknowledges FCT/MCTES for fellowship SFRH/BD/148671/2019 and the STSM grant funded by COST Action CA18238 (Ocean4Biotech). CFR is funded by national funds (OE), through FCT_Fundação para a Ciência e a Tecnologia, I.P., in the scope of the framework contract foreseen in the numbers 4,5 and 6 of the article 23, of the Decree-Law 57/2016, of 29 August, changed by Law 57/2017, of 19 July.

Institutional Review Board Statement: Not applicable.

Informed Consent Statement: Not applicable.

Data Availability Statement: All the nucleotide sequences from the 85 actinomycetes strains were deposited in GenBank under accession numbers MT830750-MT830834 available at https:/ / www.ncbi. nlm.nih.gov/genbank/, accessed on 23 September 2021. All mass spectrometry data and metadata are publicly available in MassIVE MSV000085864.

Acknowledgments: We thank Pieter C. Dorrestein for support with equipment and infrastructures, Arlette Wenzel-Storjohann (GEOMAR) for her help with the bioassays, and Yessica Parera-Valadez for assistance with data processing software.

Conflicts of Interest: The authors declare no conflict of interest.

\section{References}

1. Judd, A.; Hovland, M. Seabed Fluid Flow: The Impact on Geology, Biology and the Marine Environment; Cambridge University Press: Cambridge, UK, 2007; Volume 7, pp. 1-12. [CrossRef]

2. Haverkamp, T.H.A.; Hammer, Ø.; Jakobsen, K.S. Linking geology and microbiology: Inactive pockmarks affect sediment microbial community structure. PLOS ONE 2014, 9, e85990. [CrossRef]

3. Duarte, D.; Magalhaes, V.H.; Terrinha, P.; Ribeiro, C.; Madureira, P.; Pinheiro, L.M.; Benazzouz, O.; Kim, J.-H.; Duarte, H. Identification and characterization of fluid escape structures (pockmarks) in the Estremadura Spur, west Iberian margin. Mar. Pet. Geol. 2017, 82, 414-423. [CrossRef]

4. Blunt, J.W.; Copp, B.R.; Hu, W.-P.; Munro, M.H.G.; Northcote, P.T.; Prinsep, M.R. Marine natural products. Nat. Prod. Rep. 2007, 24, 31-86. [CrossRef] [PubMed]

5. Tanaka, Y.; Omura, S. Metabolism and products of actinomycetes: An introduction. Actinomycetologica 1990, 4, 13-14. [CrossRef]

6. Sivakumar, K.; Sahu, M.K.; Thangaradjou, T.; Kannan, L. Research on marine Actinobacteria in India. Indian J. Microbiol. 2007, 47, 186-196. [CrossRef]

7. Takizawa, M.; Colwell, R.R.; Hill, R.T. Isolation and diversity of actinomycetes in the Chesapeake Bay. Appl. Environ. Microbiol. 1993, 59, 997-1002. [CrossRef]

8. Mast, Y.; Stegmann, E. Actinomycetes: The antibiotics producers. Antibiotics 2019, 8, 105. [CrossRef]

9. Goodfellow, M.; O'Donnell, A.G. Roots of bacterial systematic. In Handbook of New Bacterial Systematics; Goodfellow, M., O'donnell, A., Eds.; Academic Press: London, UK; San Diego, CA, USA, 1993; pp. 3-54. ISBN1 9780122896729. ISBN2 0122896726.

10. Stach, J.E.M.; Maldonado, L.A.; Ward, A.C.; Goodfellow, M.; Bull, A.T. New primers for the class Actinobacteria: Application to marine and terrestrial environments. Environ. Microbiol. 2003, 5, 828-841. [CrossRef]

11. Magarvey, N.A.; Keller, J.M.; Bernan, V.; Dworkin, M.; Sherman, D.H. Isolation and characterization of novel marine-derived actinomycete taxa rich in bioactive metabolites. Appl. Environ. Microbiol. 2004, 70, 7520-7529. [CrossRef]

12. Bull, A.T.; Stach, J.E.M.; Ward, A.C.; Goodfellow, M. Marine Actinobacteria: Perspectives, challenges, future directions. Antonie Van Leeuwenhoek 2005, 87, 65-79. [CrossRef]

13. Fiedler, H.-P.; Bruntner, C.; Bull, A.T.; Ward, A.C.; Goodfellow, M.; Potterat, O.; Puder, C.; Mihm, G. Marine actinomycetes as a source of novel secondary metabolites. Antonie Van Leeuwenhoek 2005, 87, 37-42. [CrossRef]

14. Jensen, P.R.; Gontang, E.; Mafnas, C.; Mincer, T.J.; Fenical, W. Culturable marine actinomycete diversity from tropical Pacific Ocean sediments. Environ. Microbiol. 2005, 7, 1039-1048. [CrossRef] [PubMed]

15. Feling, R.H.; Buchanan, G.O.; Mincer, T.J.; Kauffman, C.A.; Jensen, P.R.; Fenical, W. Salinosporamide A: A highly cytotoxic proteasome inhibitor from a novel microbial source, a marine bacterium of the new genus Salinospora. Angew. Chem. Int. Ed. 2003, 42, 355-357. [CrossRef] 
16. Jimenez, P.C.; Wilke, D.V.; Branco, P.C.; Bauermeister, A.; Rezende-Teixeira, P.; Gaudêncio, S.P.; Costa-Lotufo, L.V. Enriching cancer pharmacology with drugs of marine origin. Br. J. Pharm. 2019, 177, 3-27. [CrossRef] [PubMed]

17. Barreca, M.; Span, V.; Montalbano, A.; Cueto, M.; Marrero, A.R.D.; Deniz, I.; Erdogan, A.; Bilela, L.L.; Moulin, C.; Taffin-deGuivenchy, E.; et al. Marine anticancer agents: An overview with a particular focus on their chemical classes. Mar. Drugs 2020, 18, 619. [CrossRef] [PubMed]

18. Schneemann, I.; Nagel, K.; Kajahn, I.; Labes, A.; Wiese, J.; Imhoff, J.F. Comprehensive investigation of marine Actinobacteria associated with the sponge Halichondria panicea. Appl Environ. Microbiol. 2010, 76, 3702-3714. [CrossRef]

19. Betancur, L.A.; Naranjo-Gaybor, S.J.; Vinchira-Villarraga, D.M.; Moreno-Sarmiento, N.C.; Maldonado, L.A.; Suarez-Moreno, Z.R.; Acosta-González, A.; Padilla-Gonzalez, G.F.; Puyana, M.; Castellanos, L.; et al. Marine Actinobacteria as a source of compounds for phytopathogen control: An integrative metabolic-profiling/bioactivity and taxonomical approach. PLoS ONE 2017, 12, e0170148. [CrossRef]

20. Kavitha, A.; Savithri, H.S. Biological significance of marine Actinobacteria of east coast of Andhra Pradesh, India. Front. Microbiol 2017, 8, 1201. [CrossRef]

21. Parera-Valadez, Y.; Yam-Puc, A.; López-Aguiar, L.K.; Borges-Argáez, R.; Figueroa-Saldivar, M.A.; Cáceres-Farfán, M.; MárquezVelázquez, N.A.; Prieto-Davó, A. Ecological strategies behind the selection of cultivable actinomycete strains from the Yucatan Peninsula for the discovery of secondary metabolites with antibiotic activity. Microb. Ecol. 2019, 77, 839-851. [CrossRef]

22. Kashfi, R.; Kelsey, C.; Gang, D.J.; Call, D.R.; Gang, D.R. Metabolomic diversity and identification of antibacterial activities of bacteria isolated from marine sediments in Hawai'i and Puerto Rico. Front. Mol. Biosci. 2020, 7, 23. [CrossRef]

23. Prieto-Davó, A.; Dias, T.; Gomes, S.E.; Rodrigues, S.; Parera-Valadez, Y.; Borralho, P.M.; Pereira, F.; Rodrigues, C.M.P.; SantosSanches, I.; Gaudêncio, S.P. The Madeira Archipelago as a significant source of marine-serived actinomycete diversity with anticancer and antimicrobial potential. Front. Microbiol. 2016, 7, 1594. [CrossRef] [PubMed]

24. Bauermeister, A.; Velasco-Alzate, K.; Dias, T.; Macedo, H.; Ferreira, E.G.; Jimenez, P.C.; Lotufo, T.M.C.; Lopes, N.P.; Gaudêncio, S.P.; Costa-Lotufo, L.V. Metabolomic fingerprinting of Salinispora from Atlantic oceanic islands. Front. Microbiol. $2018,9,3021$. [CrossRef]

25. Bauermeister, A.; Pereira, F.; Grilo, I.R.; Godinho, C.C.; Paulino, M.; Almeida, V.; Gobbo-Neto, L.; Prieto-Davó, A.; Sobral, R.G.; Lopes, N.P.; et al. Intra-clade metabolomic profiling of MAR4 Streptomyces from the Macaronesia Atlantic region reveals a source of anti-biofilm metabolites. Environ. Microbiol. 2019, 21, 1099-1112. [CrossRef]

26. Prieto-Davó, A.; Fenical, W.; Jensen, P.R. Comparative actinomycete diversity in marine sediments. Aquat. Microb. Ecol. 2008, 52, 1-11. [CrossRef]

27. Hughes, C.C.; Prieto-Davó, A.; Jensen, P.R.; Fenical, W. The Marinopyrroles, antibiotics of an unprecedented structure class from a marine Streptomyces sp. Org. Lett. 2008, 10, 629-631. [CrossRef] [PubMed]

28. Becerril-Espinosa, A.; Freel, K.C.; Jensen, P.R.; Soria-Mercado, I.E. Marine Actinobacteria from the Gulf of California: Diversity, abundance and secondary metabolite biosynthetic potential. Antonie Van Leeuwenhoek 2013, 103, 809-819. [CrossRef] [PubMed]

29. Letzel, A.-C.; Li, J.; Amos, G.C.A.; Millán-Aguiñaga, N.; Ginigini, J.; Abdelmohsen, U.R.; Gaudêncio, S.P.; Ziemert, N.; Moore, B.S.; Jensen, P.R. Genomic insights into specialized metabolism in the marine actinomycete Salinispora. Environ. Microbiol. 2017, 19, 3660-3673. [CrossRef]

30. Tsujibo, H.; Kubota, T.; Yamamoto, M.; Miyamoto, K.; Inamori, Y. Characterization of chitinase genes from an alkaliphilic actinomycete, Nocardiopsis prasina OPC-131. Appl. Environ. Microbiol. 2003, 69, 894-900. [CrossRef] [PubMed]

31. Farrell, D.; Webb, H.; Johnston, M.A.; Poulsen, T.A.; O’Meara, F.; Christensen, L.L.H.; Beier, L.; Borchert, T.V.; Nielsen, J.E. Toward fast determination of protein stability maps: Experimental and theoretical analysis of mutants of a Nocardiopsis prasina serine protease. Biochemistry 2012, 51, 5339-5347. [CrossRef]

32. Yuan, L.-J.; Zhang, Y.-Q.; Yu, L.-Y.; Sun, C.-H.; Wei, Y.-Z.; Liu, H.-Y.; Li, W.-J.; Zhang, Y.-Q. Actinopolymorpha cephalotaxi sp. nov., a novel actinomycete isolated from rhizosphere soil of the plant Cephalotaxus fortunei. Int. J. Syst. Evol. Microbiol. 2010, 60, 51-54. [CrossRef]

33. Xiong, Z.-J.; Miao, C.-P.; Zheng, Y.-K.; Liu, K.; Li, W.-J.; Liu, W.-H.; Xu, L.-H.; Zhao, L.-X. Stackebrandtia endophytica sp. nov., an actinobacterium isolated from Tripterygium wilfordii. Int. J. Syst. Evol. Microbiol. 2015, 65, 1709-1713. [CrossRef]

34. Liu, M.-J.; Jin, C.-Z.; Park, D.-J.; Asem, M.D.; Xiao, M.; Salam, N.; Li, W.-J.; Kim, C.-J. Stackebrandtia soli sp. nov., a novel actinobacterium isolated from a soil sample. Int. J. Syst. Evol. Microbiol. 2018, 68, 1215-1219. [CrossRef]

35. Farnaes, L.; Coufal, N.G.; Kauffman, C.A.; Rheingold, A.L.; DiPasquale, A.G.; Jensen, P.R.; Fenical, W. Napyradiomycin derivatives, produced by a marine-derived actinomycete, illustrate cytotoxicity by induction of apoptosis. J. Nat. Prod. 2014, 77, 15-21. [CrossRef]

36. Pereira, F.; Almeida, J.R.; Paulino, M.; Grilo, R.I.; Macedo, H.; Cunha, I.; Sobral, R.G.; Vasconcelos, V.; Gaudêncio, S.P. Antifouling napyradiomycins from marine-derived actinomycetes Streptomyces aculeolatus. Mar. Drugs 2020, 18, 63. [CrossRef] [PubMed]

37. Taddei, A.; Rodríguez, M.J.; Márquez-Vilchez, E.; Castelli, C. Isolation and identification of Streptomyces spp. from Venezuelan soils: Morphological and biochemical studies. I. Microbiol. Res. 2006, 161, 222-231. [CrossRef]

38. Gao, R.; Liu, C.; Zhao, J.; Jia, F.; Yu, C.; Yang, L.; Wang, X.; Xiang, W. Micromonospora jinlongensis sp. nov., isolated from muddy soil in China and emended description of the genus Micromonospora. Antonie Van Leeuwenhoek 2014, 105, 307-315. [CrossRef]

39. Shen, Y.; Zhang, Y.; Liu, C.; Wang, X.; Zhao, J.; Jia, F.; Yang, L.; Yang, D.; Xiang, W. Micromonospora zeae sp. nov., a novel endophytic actinomycete isolated from corn root (Zea mays L.). J. Antibiot. 2014, 67, 739-743. [CrossRef] 
40. Zhao, S.; Liu, C.; Zheng, W.; Ma, Z.; Cao, T.; Zhao, J.; Yan, K.; Xiang, W.; Wang, X. Micromonospora parathelypteridis sp. nov., an endophytic actinomycete with antifungal activity isolated from the root of Parathelypteris beddomei (Bak.) Ching. Int. J. Syst. Evol. Microbiol. 2017, 67, 268-274. [CrossRef]

41. Zhao, J.; Guo, L.; He, H.; Liu, C.; Zhang, Y.; Li, C.; Wang, X.; Xiang, W. Micromonospora taraxaci sp. nov., a novel endophytic actinomycete isolated from dandelion root (Taraxacum mongolicum Hand.-Mazz.). Antonie Van Leeuwenhoek 2014, 106, 667-674. [CrossRef] [PubMed]

42. Riesco, R.; Carro, L.; Roman-Ponce, B.; Prieto, C.; Blom, J.; Klenk, H.P.; Normand, P.; Trujillo, M.E. Defining the species Micromonospora saelicesensis and Micromonospora noduli under the framework of genomics. Front. Microbiol. 2018, 9, 1360. [CrossRef] [PubMed]

43. Chao, A.; Chiu, C.-H. Species Richness: Estimation and Comparison; Balakrishnan, N., Colton, T., Everitt, W., Piegorsch, B., Ruggeri, F., Teugels, J.L., Eds.; Wiley StatsRef Stat. Ref. Online; John Wiley \& Sons, Ltd.: Chichester, UK, 2016; pp. 1-26.

44. Jensen, P.R.; Williams, P.G.; Dong-Chan, O.; Zeigler, L.; Fenical, W. Species-specific secondary metabolite production in marine actinomycetes of the genus Salinispora. Appl. Environ. Microbiol. 2007, 73, 1146-1152. [CrossRef]

45. Román-Ponce, B.; Millán-Aguiñaga, N.; Guillen-Matus, D.; Chase, A.B.; Ginigini, J.G.M.; Soapi, K.; Feussner, K.D.; Jensen, P.R.; Trujillo, M.E. Six novel species of the obligate marine actinobacterium Salinispora, Salinispora cortesiana sp. nov., Salinispora fenicalii sp. nov., Salinispora goodfellowii sp. nov., Salinispora mooreana sp. nov., Salinispora oceanensis sp. nov. and Salinispora vitien. Int. J. Syst. Evol. Microbiol. 2020, 70, 4668-4682. [CrossRef]

46. Gaudêncio, S.P.; Pereira, F. Dereplication: Racing to speed up the natural products discovery process. Nat. Prod. Rep. 2015, 32, 779-810. [CrossRef] [PubMed]

47. Wang, M.; Carver, J.J.; Phelan, V.V.; Sanchez, L.M.; Garg, N.; Peng, Y.; Nguyen, D.D.; Watrous, J.; Kapono, C.A.; Luzzatto-Knaan, T.; et al. Sharing and community curation of mass spectrometry data with Global Natural Products Social Molecular Networking Nat. Biotechnol. 2016, 34, 828-837. [CrossRef] [PubMed]

48. Sheehan, J.C.; Zachau, H.G.; Lawson, W.B. The structure of etamycin. J. Am. Chem. Soc. 1957, 79, 3933-3934. [CrossRef]

49. Barrow, C.J.; Oleynek, J.J.; Marinelli, V.; Sun, H.H.; Kaplita, P.; Sedlock, D.M.; Gillum, A.M.; Chadwick, C.C.; Cooper, R. Antimycins, inhibitors of ATP-citrate lyase, from a Streptomyces sp. J. Antibiot. 1997, 50, 729-733. [CrossRef] [PubMed]

50. Sumner, L.W.; Amberg, A.; Barrett, D.; Beale, M.H.; Beger, R.; Daykin, C.A.; Fan, T.W.-M.; Fiehn, O.; Goodacre, R.; Griffin, J.L.; et al. Proposed minimum reporting standards for chemical analysis Chemical Analysis Working Group (CAWG) Metabolomics Standards Initiative (MSI). Metabolomics 2007, 3, 211-221. [CrossRef]

51. Takada, K.; Ninomiya, A.; Naruse, M.; Sun, Y.; Miyazaki, M.; Nogi, Y.; Okada, S.; Matsunaga, S. Surugamides A-E, cyclic octapeptides with four d-amino acid residues, from a marine Streptomyces sp.: LC-MS-aided inspection of partial hydrolysates for the distinction of D- and L-amino acid residues in the sequence. J. Org. Chem. 2013, 78, 6746-6750. [CrossRef]

52. Caraballo-Rodríguez, A.M.; Dorrestein, P.C.; Pupo, M.T. Molecular inter-kingdom interactions of endophytes isolated from Lychnophora ericoides. Sci. Rep. 2017, 7, 5373. [CrossRef]

53. Matsuda, K.; Kuranaga, T.; Sano, A.; Ninomiya, A.; Takada, K.; Wakimoto, T. The revised structure of the cyclic octapeptide surugamide A. Chem. Pharm. Bull. 2019, 67, 476-480. [CrossRef]

54. Gobec, S.; Frlan, R. Inhibitors of cathepsin B. Curr. Med. Chem. 2006, 13, 2309-2327. [CrossRef] [PubMed]

55. Velasco-Alzate, K.Y.; Bauermeister, A.; Tangerina, M.M.P.; Lotufo, T.M.C.; Ferreira, M.J.P.; Jimenez, P.C.; Padilla, G.; Lopes, N.P.; Costa-Lotufo, L.V. Marine bacteria from Rocas Atoll as a rich source of pharmacologically active compounds. Mar. Drugs 2019, 17, 671. [CrossRef]

56. Neft, N.; Farley, T.M. Conditions influencing antimycin production by a Streptomyces species grown in chemically defined medium. Antimicrob. Agents Chemother. 1972, 1, 274-276. [CrossRef]

57. Abidi, S.L. High-performance liquid chromatographic resolution and quantification of a dilactonic antibiotic mixture (antimycin A). J. Chromatogr. 1982, 234, 187-200. [CrossRef]

58. Guidarelli, A.; Brambilla, L.; Rota, C.; Tomasi, A.; Cattabeni, F.; Cantoni, O. The respiratory-chain poison antimycin A promotes the formation of DNA single-strand breaks and reduces toxicity in U937 cells exposed to t-butylhydroperoxide. Biochem. J. 1996, 317, 371-375. [CrossRef] [PubMed]

59. Kim, H.; Esser, L.; Hossain, M.B.; Xia, D.; Yu, C.-A.; Rizo, J.; van der Helm, D.; Deisenhofer, J. Structure of antimycin A1, a specific electron transfer inhibitor of ubiquinol-cytochrome c oxidoreductase. J. Am. Chem. Soc. 1999, 121, 4902-4903. [CrossRef]

60. Carcia-Mendoza, C. Studies on the made action of etamycin (viridogrisein). Biochim. Biophys. Acta-Gen. Subj. 1965, 97, 394-396. [CrossRef]

61. Haste, N.M.; Perera, V.R.; Maloney, K.N.; Tran, D.N.; Jensen, P.; Fenical, W.; Nizet, V.; Hensler, M.E. Activity of the streptogramin antibiotic etamycin against methicillin-resistant Staphylococcus aureus. J. Antibiot. 2010, 63, 219-224. [CrossRef]

62. Rothberger, J.C. Ueber die gegenseitigen Beziehungen zwischen curare und physostigmin. Archiv für die gesamte Physiologie des Menschen und der Tiere 1901, 87, 117-169. [CrossRef]

63. Wright, J.L.C. A new antibiotic from the marine Bryozoan Flustra foliaceae. J. Nat. Prod. 1984, 47, 893-895. [CrossRef]

64. Kobayakawa, F.; Kodani, S. Screening of streptomycetes for production of desferrioxamines. J. Pure Appl. Microbiol. 2012, 6, 1553-1558.

65. Patzer, S.I.; Braun, V. Gene cluster involved in the biosynthesis of griseobactin, a catechol-peptide siderophore of Streptomyces sp. ATCC 700974. J. Bacteriol. 2020, 192, 426-435. [CrossRef] [PubMed] 
66. Jomon, K.; Kuroda, Y.; Ajisaka, M.; Sakai, H. A new antibiotic, ikarugamycin. J. Antibiot. 1972, 25, 271-280. [CrossRef] [PubMed]

67. Zhang, G.; Zhang, W.; Zhang, Q.; Shi, T.; Ma, L.; Zhu, Y.; Li, S.; Zhang, H.; Zhao, Y.-L.; Shi, R.; et al. Mechanistic insights into polycycle formation by reductive cyclization in ikarugamycin biosynthesis. Angew. Chem. Int. Ed. Engl. 2014, 53, 4840-4844. [CrossRef]

68. Zhou, X.; Fenical, W. The unique chemistry and biology of the piericidins. J. Antibiot. 2016, 69, 582-593. [CrossRef]

69. Tsakos, M.; Jacobsen, K.M.; Yu, W.; Villadsen, N.L.; Poulsen, T.B. The rakicidin family of anticancer natural products-synthetic strategies towards a new class of hypoxia-selective cytotoxins. Synlett 2016, 27, 1898-1906. [CrossRef]

70. Kitani, S.; Ueguchi, T.; Igarashi, Y.; Leetanasaksakul, K.; Thamchaipenet, A.; Nihira, T. Rakicidin F, a new antibacterial cyclic depsipeptide from a marine sponge-derived Streptomyces sp. J. Antibiot. 2018, 71, 139-141. [CrossRef] [PubMed]

71. Kuranaga, T.; Fukuba, A.; Ninomiya, A.; Takada, K.; Matsunaga, S.; Wakimoto, T. Diastereoselective total synthesis and structural confirmation of surugamide F. Chem. Pharm. Bull. 2018, 66, 637-641. [CrossRef]

72. Sun, P.; Maloney, K.N.; Nam, S.-J.; Haste, N.M.; Raju, R.; Aalbersberg, W.; Jensen, P.R.; Nizet, V.; Hensler, M.E.; Fenical, W. Fijimycins A-C, three antibacterial etamycin-class depsipeptides from a marine-derived Streptomyces sp. Bioorg. Med. Chem. 2011, 19, 6557-6562. [CrossRef]

73. Tripathi, A.; Vázquez-Baeza, Y.; Gauglitz, J.M.; Wang, M.; Dührkop, K.; Nothias-Esposito, M.; Acharya, D.D.; Ernst, M.; van der Hooft, J.J.J.; Zhu, Q.; et al. Chemically-informed analyses of metabolomics mass spectrometry data with Qemistree. bioRxiv 2020, 17, 146-151. [CrossRef]

74. Dührkop, K.; Shen, H.; Meusel, M.; Rousu, J.; Böcker, S. Searching molecular structure databases with tandem mass spectra using CSI:FingerID. Proc. Natl. Acad. Sci. USA 2015, 112, 12580-12585. [CrossRef]

75. Caldwell, S.L.; Laidler, J.R.; Brewer, E.A.; Eberly, J.O.; Sandborgh, S.C.; Colwell, F.S. Anaerobic Oxidation of Methane: Mechanisms, Bioenergetics, and the Ecology of Associated Microorganisms. Environ. Sci. Technol. 2008, 42, 6791-6799. [CrossRef]

76. Setianingrum, F.; Rautemaa-Richardson, R.; Denning, D.W. Pulmonary cryptococcosis: A review of pathobiology and clinical aspects. Med. Mycol. 2019, 57, 133-150. [CrossRef] [PubMed]

77. Poley, M.; Koubek, R.; Walsh, L.; Mcgillen, B. Cryptococcal meningitis in an apparent immunocompetent patient. J. Investig. Med. High. Impact Case Rep. 2019, 7, 1-5. [CrossRef]

78. Havlickova, B.; Czaika, V.A.; Friedrich, M. Epidemiological trends in skin mycoses worldwide. Mycoses 2008, 51, 2-15. [CrossRef] [PubMed]

79. Roca, C.; Lehmann, M.; Torres, C.A.V.; Baptista, S.; Gaudêncio, S.P.; Freitas, F.; Reis, M.A.M. Exopolysaccharide production by a marine Pseudoalteromonas sp. strain isolated from Madeira Archipelago ocean sediments. New Biotechnol. 2016, 33, 460-466. [CrossRef] [PubMed]

80. Mincer, T.J.; Jensen, P.R.; Kauffman, C.A.; Fenical, W. Widespread and persistent populations of a major new marine actinomycete taxon in ocean sediments. Appl. Environ. Microbiol. 2002, 68, 5005-5011. [CrossRef] [PubMed]

81. Gontang, E.A.; Fenical, W.; Jensen, P.R. Phylogenetic diversity of gram-positive bacteria cultured from marine sediments. Appl. Environ. Microbiol. 2007, 73, 3272-3282. [CrossRef] [PubMed]

82. Waterhouse, A.M.; Procter, J.B.; Martin, D.M.A.; Clamp, M.; Barton, G.J. Jalview Version 2-A multiple sequence alignment editor and analysis workbench. Bioinformatics 2009, 25, 1189-1191. [CrossRef]

83. Katoh, K.; Misawa, K.; Kuma, K.; Miyata, T. MAFFT: A novel method for rapid multiple sequence alignment based on fast Fourier transform. Nucleic Acids Res. 2002, 30, 3059-3066. [CrossRef] [PubMed]

84. Chun, J.; Lee, J.-H.; Jung, Y.; Kim, M.; Kim, S.; Kim, B.K.; Lim, Y.-W. EzTaxon: A web-based tool for the identification of prokaryotes based on $16 S$ ribosomal RNA gene sequences. Int. J. Syst. Evol. Microbiol. 2007, 57, 2259-2261. [CrossRef]

85. Zhang, Z.; Schwartz, S.; Wagner, L.; Miller, W. A greedy algorithm for aligning DNA sequences. J. Comput. Biol. 2000, 7, 203-214. [CrossRef]

86. Hall, B.G. Building phylogenetic trees from molecular data with MEGA. Mol. Biol. Evol. 2013, 30, 1229-1235. [CrossRef]

87. Tamura, K.; Stecher, G.; Peterson, D.; Filipski, A.; Kumar, S. MEGA6: Molecular Evolutionary Genetics Analysis version 6.0. Mol. Biol. Evol. 2013, 30, 2725-2729. [CrossRef]

88. Hoff, M.; Orf, S.; Riehm, B.; Darriba, D.; Stamatakis, A. Does the choice of nucleotide substitution models matter topologically? BMC Bioinform. 2016, 17, 143. [CrossRef]

89. Schloss, P.D.; Westcott, S.L.; Ryabin, T.; Hall, J.R.; Hartmann, M.; Hollister, E.B.; Lesniewski, R.A.; Oakley, B.B.; Parks, D.H.; Robinson, C.J.; et al. Introducing mothur: Open-source, platform-independent, community-supported software for describing and comparing microbial communities. Appl. Environ. Microbiol. 2009, 75, 7537-7541. [CrossRef] [PubMed]

90. Chao, A. Estimating the population size for capture-recapture data with unequal catchability. Biometrics 1987, 43, 783-791. [CrossRef] [PubMed]

91. Huggins, R.; Stoklosa, J.; Roach, C.; Yip, P. Estimating the size of an open population using sparse capture-recapture data. Biometrics 2018, 74, 280-288. [CrossRef]

92. Kim, B.-R.; Shin, J.; Guevarra, R.; Lee, J.H.; Kim, D.W.; Seol, K.-H.; Lee, J.-H.; Kim, H.B.; Isaacson, R. Deciphering diversity indices for a better understanding of microbial communities. J. Microbiol. Biotechnol. 2017, 27, 2089-2093. [CrossRef]

93. Aron, A.; Petras, D.; Schmid, R.; Gauglitz, J.M.; Büttel, I.; Antelo, L.; Zhi, H.; Saak, C.C.; Malarney, K.P.; Thines, E.; et al. Native electrospray-based metabolomics enables the detection of metal-binding compounds. bioRxiv 2019, 824888. [CrossRef] 
94. Kessner, D.; Chambers, M.; Burke, R.; Agus, D.; Mallick, P. ProteoWizard: Open source software for rapid proteomics tools development. Bioinformatics 2008, 24, 2534-2536. [CrossRef] [PubMed]

95. Adusumilli, R.; Mallick, P. Data conversion with ProteoWizard msConvert. Methods Mol. Biol. 2017, 1550, 339-368. [CrossRef]

96. Katajamaa, M.; Miettinen, J.; Oresic, M. MZmine: Toolbox for processing and visualization of mass spectrometry based molecular profile data. Bioinformatics 2006, 22, 634-636. [CrossRef] [PubMed]

97. Pluskal, T.; Castillo, S.; Villar-Briones, A.; Orešič, M. MZmine 2: Modular framework for processing, visualizing, and analyzing mass spectrometry-based molecular profile data. BMC Bioinform. 2010, 11, 395. [CrossRef] [PubMed]

98. Myers, O.D.; Sumner, S.J.; Li, S.; Barnes, S.; Du, X. Detailed investigation and comparison of the XCMS and MZmine 2 chromatogram construction and chromatographic peak detection methods for preprocessing mass spectrometry metabolomics data. Anal. Chem. 2017, 89, 8689-8695. [CrossRef] [PubMed]

99. Shannon, P.; Markiel, A.; Ozier, O.; Baliga, N.S.; Wang, J.T.; Rama7ge, D.; Amin, N.; Schwikowski, B.; Ideker, T. Cytoscape: A software environment for integrated models of biomolecular interaction networks. Genome Res. 2003, 13, 2498-2504. [CrossRef]

100. Letunic, I.; Bork, P. Interactive Tree Of Life (iTOL) v4: Recent updates and new developments. Nucleic Acids Res. 2019, 47, W256-W259. [CrossRef] 